\title{
SINGLE METAL ZIRCONIUM NON-EVAPORABLE GETTER COATING
}

\author{
R. Širvinskaitė ${ }^{\dagger 1}$, Loughborough University, LE11 3TU Loughborough, UK \\ O. B. Malyshev, R. Valizadeh, A. Hannah, STFC ASTeC Daresbury Laboratory, WA4 4AD \\ Warrington, UK \\ M. D. Cropper, Loughborough University, LE11 3TU Loughborough, UK \\ ${ }^{1}$ also at STFC ASTeC Daresbury Laboratory, WA4 4AD Warrington, UK
}

\begin{abstract}
Non-evaporable getter (NEG) coating has been used for years in many particle accelerator facilities due to its evenly distributed pumping speed, low thermal outgassing, and low photon and electron stimulated desorption yields. In our earlier work, it has been demonstrated that quaternary Ti-Zr-Hf-V coating deposited from an alloy target in a form of a rod has the lowest desorption yields, the highest sticking probability and sorption capacity. In this paper, a single element $\mathrm{Zr}$ target has been explored. This type of target is widely available and produced in a form of a wire that is easy to apply for a uniform coating of various shapes of vacuum chambers. Two samples coated with $\mathrm{Zr}$ film of dense and columnar structure were analysed and results of the pumping properties and electron stimulated desorption results are reported. The results show that pure $\mathrm{Zr}$ coating could be an economic solution, despite not being as effective as can be achieved with a quaternary NEG film. It shows that columnar $\mathrm{Zr}$ coating can be activated and reaches full pumping capacity at $160{ }^{\circ} \mathrm{C}$. This is close to the activation temperature of Ti-Zr-Hf-V film and lower than that for the widely used ternary Ti-Zr-V film. Single metal $\mathrm{Zr}$ coatings demonstrated that it could be a more efficient and inexpensive way of producing the NEG-coated vacuum chambers.
\end{abstract}

\section{INTRODUCTION}

The non-evaporable getter (NEG) coating was invented at CERN [1-5] and since then has become a major component of particle accelerator vacuum systems. It provides distributed pumping along vacuum chambers with large aspect ratios ( $L / d$, where $L$ is length and $d$ is the transverse dimension), thus reducing the number of external pumps required to meet specified UHV pressures. In addition, in the application of the coating on accelerator chambers, the NEG coating creates a diffusion barrier and allows reduction of the electron, photon and ion stimulated desorption yields and, therefore, makes it easier to maintain specified pressure in the accelerator beam vacuum chamber.

The key parameters for the design of an accelerator vacuum chamber are the following:

- The thermal outgassing, which is negligible for an activated NEG coating [6].

- The dynamic outgassing from the surface due to electron or photon bombardment called photon and electron stimulated desorption (PSD and ESD), which are defined by PSD or ESD yields as a number of desorbed molecules per impact particle: $\eta$ (molecules/electron or molecules/photon).

- The distributed pumping is typically described by the sticking probability $\alpha$ of the NEG coating.

The gas density, $n$, in accelerator vacuum chambers depends on both desorption and pumping, thus in long chambers: $n \propto \eta / \alpha$. Previous results with various NEG coatings demonstrated that $\eta_{\mathrm{H}_{2}} \leq 0.01, \eta_{\mathrm{CO}} \leq 0.5$ and $\eta_{\mathrm{CO}_{2}} \leq 0.6[3-5,6$ 7]. The initial effort in NEG coating development was to reduce the NEG activation temperature by studying the effect of composition using $\mathrm{Ti}, \mathrm{Zr}$ and $\mathrm{V}$ [5], this results in Ti-Zr-V film which can be activated at $180{ }^{\circ} \mathrm{C}$. Further reduction of 
activation temperature was achieved by adding $\mathrm{Hf}$ to reduce the grain size further and increase the grain boundary density. The activation temperature of $160{ }^{\circ} \mathrm{C}$ was achieved with columnar Ti-Zr-Hf-V film deposited from a target made of four single element twisted wires [8]. However, deposition from twisted wire targets does not provide a uniform composition of the coating. Thus, the lowest activation temperature of $150{ }^{\circ} \mathrm{C}$ was achieved with columnar Ti$\mathrm{Zr}-\mathrm{Hf}-\mathrm{V}$ film deposited from an alloy target [8-9]. A deposition from ternary Ti-Zr-V alloy target also reduces the lowest activation temperature to $160^{\circ} \mathrm{C}$.

The sticking probability cannot be greater than one; therefore, the further optimisation of the pumping properties is difficult, and the emphasis should be on reducing electron stimulated desorption yields (ESD) [10-12]. The lowest ESD was obtained with dense Ti-Zr-V and Ti-Zr-Hf-V films [10-11]. The further reduction of the ESD yields was achieved by vacuum-firing the substrate before deposition [12]. The best pumping properties were obtained with columnar Ti-Zr$\mathrm{V}$ and Ti-Zr-Hf-V films [7-8]. A combination of two layers into one NEG coating allows combining the lowest ESD and highest pumping properties [12].

All results above require depositing from either twisted wire or alloy targets. A deposition from a target made of twisted single metal wires could result in non-uniform NEG coating, and the twisted wire target could take more space than a single wire; therefore, making it difficult to be applied for narrow gap chambers. An alloy target provides uniform coating and results in better pumping properties; however, there is a very limited number of providers of these targets and dealing with such target requires greater care. A single metal coating would allow for easier deposition as the target would be cheaper, thinner and widely available. This paper reports on the results of deposition from a single metal $\mathrm{Zr}$ target, which is a well-known metallic getter usually used for compound NEG materials due to its high oxygen solubility, e.g. ZrFe NEG cartridges, ternary Ti-Zr-V and quaternary Ti-Zr-Hf-V films.

The efficiency of activation of single, dual and ternary NEG coating was studied at CERN (on flat samples) using $R$ criterion for Auger Electron Spectroscopy results (the ratio between the intensity of the metallic $\mathrm{Zr}$ peak at $147 \mathrm{eV}$ and the $\mathrm{Zr}$ peak at $141 \mathrm{eV}$ corresponding to $\mathrm{ZrO}_{2}$ surface concentration) obtained from planar samples [5]. These results concluded that the presence of the three elements is necessary to obtain nanocrystalline morphology and a strong correlation between structure and activation behaviour. From these results, one can conclude that the most promising NEG coating composition is $\mathrm{Ti}_{\mathrm{x}} \mathrm{Zr}_{\mathrm{y}} \mathrm{V}_{\mathrm{z}}$ could be provided for $0 \leq \mathrm{x} \leq 0.4,0.2 \leq \mathrm{y} \leq 0.8$ and $0.2 \leq \mathrm{z} \leq 0.8$. However, as mentioned in the paper, the validity $\mathrm{R}$ criterion should be verified by pumping speed measurements.

Pumping properties of single, dual, ternary and quaternary NEG coating based on various combinations of Ti, Zr, V and $\mathrm{Hf}$ have been also studied in ASTeC Vacuum Solutions Group based on direct pumping properties measurements with a tubular sample [7-9, 14-15]. It was found that the pumping properties of the films containing $\mathrm{Zr}$ were always higher than those without it. Therefore, there was an attraction to the investigation of Zr-based NEG films, starting with a pure $\mathrm{Zr}$ coating.

In this paper the pumping properties and ESD results are reported for pure Zr getter films for the first time.

\section{DEPOSITION}

Two samples were cleaned in an ultrasonic bath with a solvent following the standard Daresbury Laboratory procedure and then deposited. The substrates were $316 \mathrm{LN}$ stainless steel tubular samples with a length of $50 \mathrm{~cm}$ and an inner diameter of $38 \mathrm{~mm}$ equipped with CF40 flanges on both sides. The deposition facility is described in detail in ref. [7]. A pure $\mathrm{Zr}$ target in a form of a 1-mm diameter wire was used for the deposition. After installing the sample 
substrate, the deposition facility was baked at $150{ }^{\circ} \mathrm{C}$ for four days. After cooling down, the pressure in the system was approximately $2 \times 10^{-9}$ mbar. The deposition parameters are described in Table 1 .

The first sample was coated with dense $\mathrm{Zr}$ film; the second one had a columnar structure, as shown in Fig. 1. The images were obtained using High Resolution Scanning Electron Microscopy (HR SEM). Images in Figs. 2-3 show the elemental analysis of the NEG layer on the stainless steel substrate. Energy Dispersive X-Ray Spectroscopy (EDX) was used to analyse the elemental composition of the film. The $\mathrm{Zr}$ makes up the thin coating layer, while nickel and iron are detected in the substrate. The analysis was done after all experiments with samples were completed; the tubes were exposed to air for about one year between the experiments and the analysis. The EDX analysis in Figs. 2 and 3 possibly illustrates the different effect that this long exposure to air has had on the films. The dense film (Fig. 2) shows only a thin oxide, whereas the columnar film has a thicker oxide around $500 \mathrm{~nm}$ (Fig. 3). The observed surface oxide develops each time the film is exposed to an oxidising atmosphere such as air. The deliberately engineered columnar structure interacts with the outside atmosphere through a surface volume. Hence the depth of interacting surface depends on compactness of the column structure. In the case of dense film, the film interacts with the outside atmosphere through the surface area. The only surface directly exposed to the oxidising atmosphere is the very top layer and the oxidation is limited to the native oxide depth.

Table 1: Deposition parameters

\begin{tabular}{lcc}
\hline Parameter & Dense & Columnar \\
\hline Gas & $\mathrm{Kr}$ & $\mathrm{Kr}$ \\
Pressure & $10^{-3} \mathrm{mbar}$ & $0.1 \mathrm{mbar}$ \\
Power supply & Pulsed DC & $\mathrm{DC}$ \\
Power & $100 \mathrm{~W}$ & $100 \mathrm{~W}$ \\
Temperature & $90-110{ }^{\circ} \mathrm{C}$ & $90-110^{\circ} \mathrm{C}$ \\
Duration & 5 hours & 5 hours \\
Film thickness & $1 \mu \mathrm{m}$ & $1.7 \mu \mathrm{m}$ \\
\hline
\end{tabular}
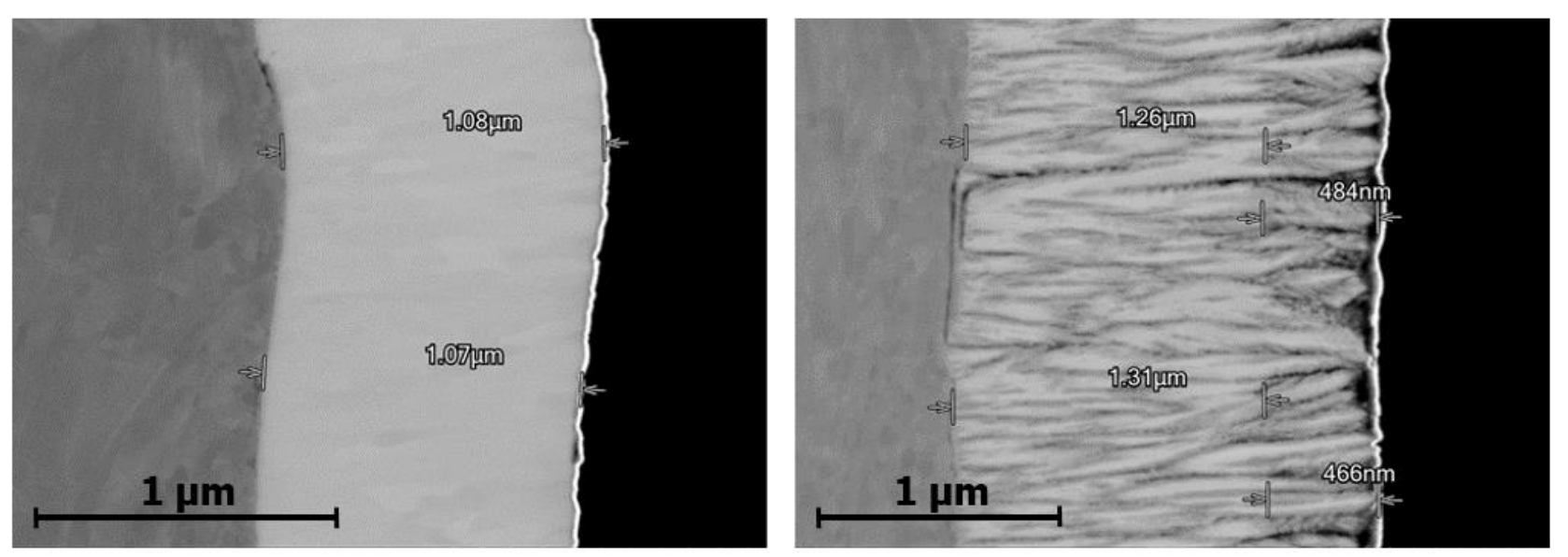

Figure 1: HR SEM cross-sectional images of dense (left) and columnar (right) NEG coating. 

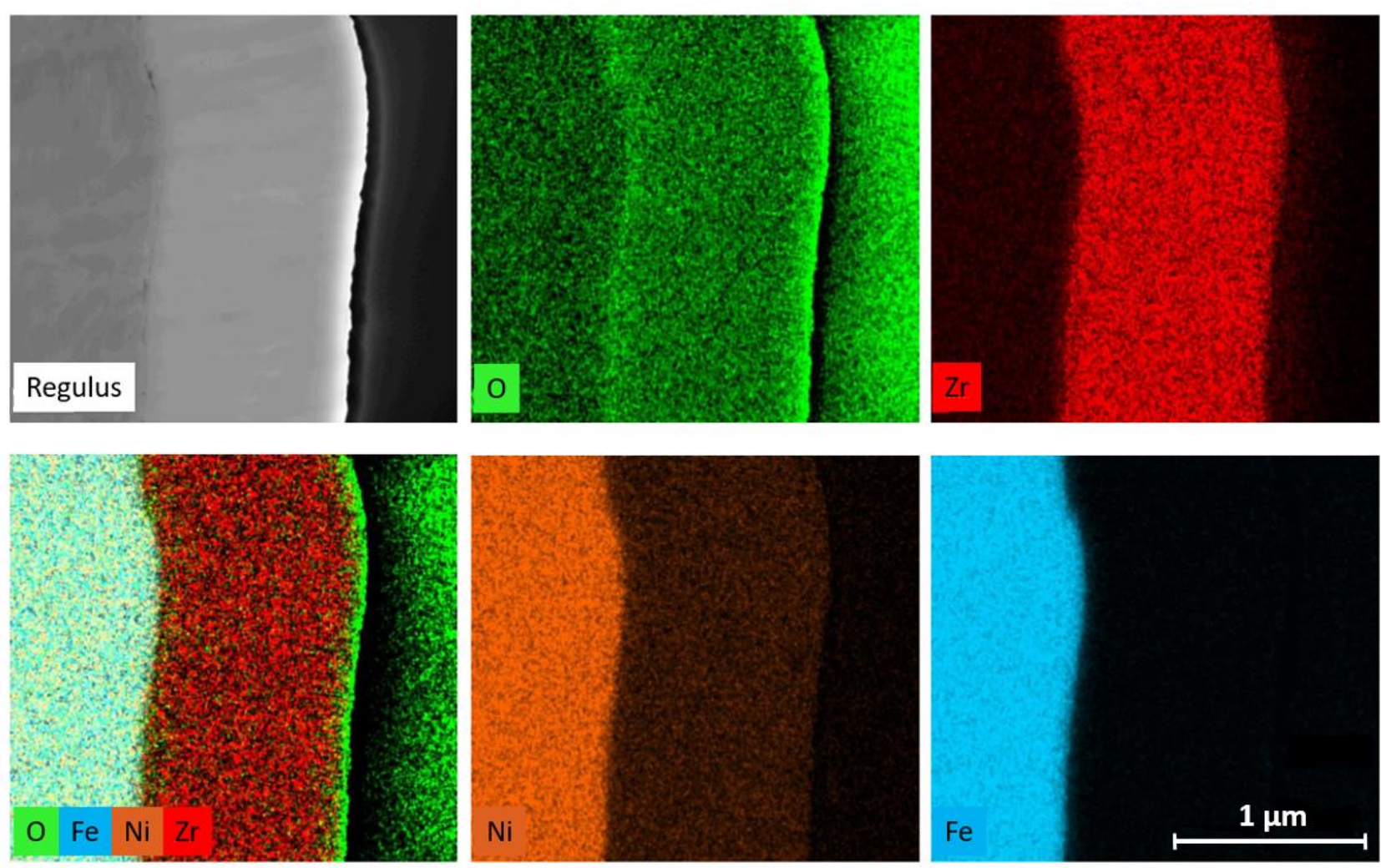

Figure 2: EDX elemental analysis of the dense NEG coating.
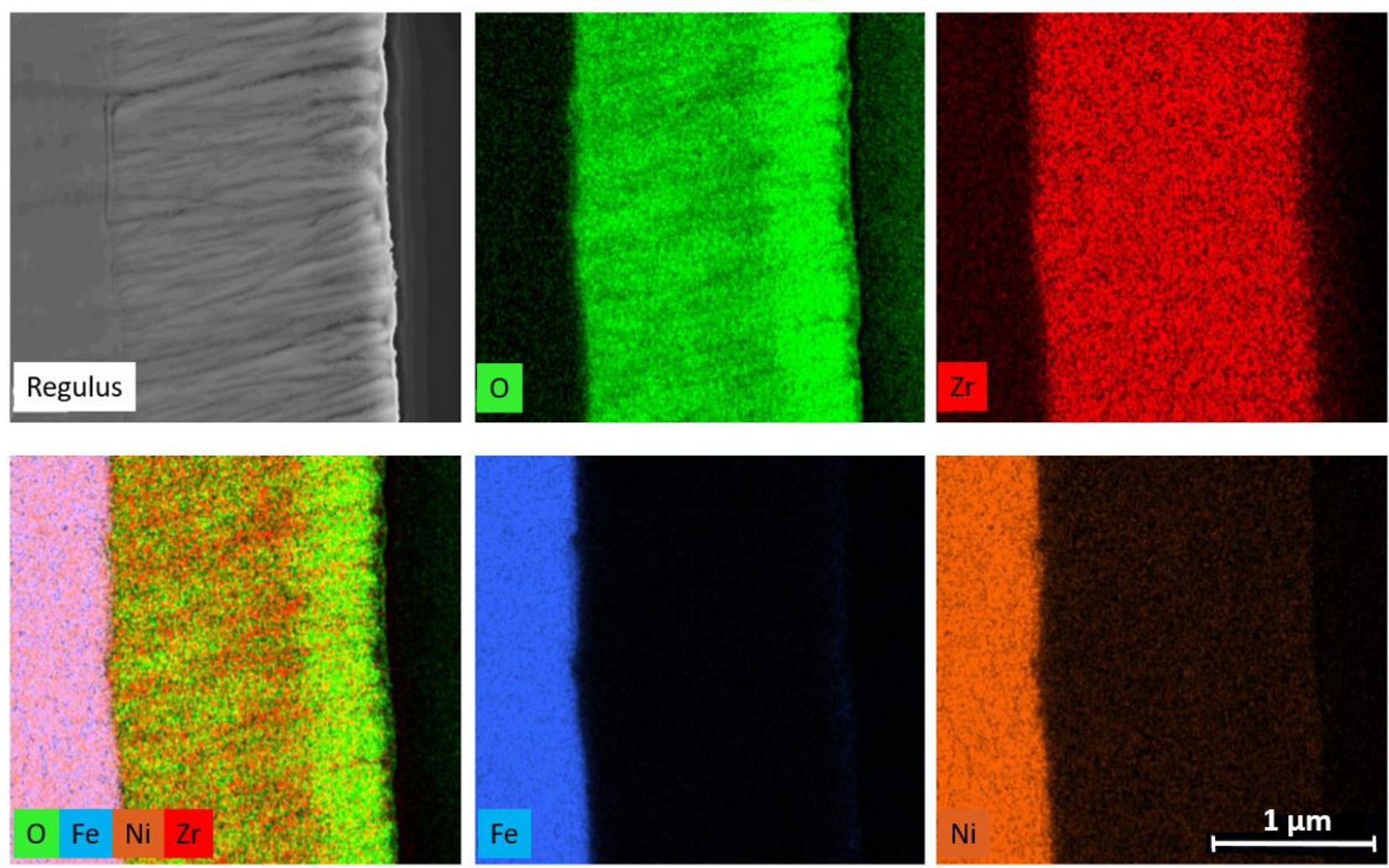

Figure 3: EDX elemental analysis of the columnar NEG coating. 


\section{EXPERIMENTAL FACILITY AND PROCEDURE}

After deposition, the substrates were vented to and stored in nitrogen. The samples were exposed to air for a short time just before installation on the NEG-characterisation facility in ASTeC, STFC Daresbury Laboratory [7, 16-17], shown in Fig. 4. The facility consists of gas injection line, pumping line and a test chamber equipped with an extractor gauge and two residual gas analysers (RGAs). The facility allows two layouts - Fig. 4(a) shows a layout for pumping properties measurements and Fig. 4(b) is its modification for ESD measurements.

These two types of measurements were performed with each sample. First, pumping properties were investigated for the activation temperatures in the range from 140 to $300{ }^{\circ} \mathrm{C}$. Then, after changing the layout, the ESD yields from the samples were measured after baking to $80,150,180$ and $250{ }^{\circ} \mathrm{C}$.

\subsection{Pumping properties measurements}

The pumping properties measurements are performed with a layout as shown in Fig. 4(a). In this case, the top RGA is installed right above the sample tube.

\subsubsection{Activation procedure}

The ASTeC standard activation procedure was applied to activate and analyse the samples [16]. After tube installation and a leak check, the test chamber was baked to $200{ }^{\circ} \mathrm{C}$ for 24 hours, while the NEG coated sample tube was kept at the temperature $T_{s} \approx 80{ }^{\circ} \mathrm{C}$. This is necessary to outgas the uncoated chamber parts and avoid sample activation at the same time. Then, the test chamber was cooled down to $150{ }^{\circ} \mathrm{C}$, extractor gauge and RGAs were switched on and degassed, then the NEG coated sample tube was heated up to the lowest activation temperature of $140{ }^{\circ} \mathrm{C}$ for 24 hours. Two hours after reaching the sample temperature of $140{ }^{\circ} \mathrm{C}$, the test chamber started cooling down to room temperature. Temperature ramping up/down rate for heating and cooling was $50{ }^{\circ} \mathrm{C} /$ hour. Pumping properties measurements were started after approximately 12-16 hours (left overnight) after the end of NEG activation.

After measurements of the pumping properties, the NEG coating was reactivated by heating the NEG coated tube to $T_{s}=150,160,180,200,220,250$ and $300^{\circ} \mathrm{C}$.

\subsubsection{Measurement procedure}

To find the sticking probability of the NEG material, selected gases $\left(\mathrm{H}_{2}, \mathrm{CO}\right.$ and $\left.\mathrm{CO}_{2}\right)$ were injected into the test chamber through a gas injection line at the bottom of the NEG tube. First, $\mathrm{H}_{2}$ initial sticking probability measurements were performed in a short $\mathrm{H}_{2}$ injection (3-5 min at $P_{2} \leq 3 \times 10^{-9} \mathrm{mbar}$, to minimise NEG saturation). Then, initial CO and $\mathrm{CO}_{2}$ sticking probability and $\mathrm{CO}$ pumping capacity were measured by injection of a mixture of $\mathrm{CO}(90 \%)$ and $\mathrm{CO}_{2}$ (10\%) until full saturation ( $P_{1} \approx P_{2} \approx 5 \times 10^{-6}$ mbar). Partial pressures $P_{1}$ and $P_{2}$ were measured by using residual gas analysers (RGAs) at the top and bottom of the tube, respectively. During the gas injection, the valves to the other pumps were closed; therefore we observed the pumping effect of the NEG film only. The ratios of partial gas pressures were calculated and used for the sticking probability and pumping capacity calculations using the results of test particle Monte Carlo (TPMC) modelling described below. 


\subsection{ESD measurements}

To provide the NEG coating testing in an accelerator-like environment, the ESD measurement facility in ASTeC allows uniform bombardment with electrons along the sample tube. The source of electrons is a 48 -cm long thoriated tungsten filament placed along the central axis of the sample tube. This requires some modification of the test facility: the top RGA was replaced with a tee-piece connected to the top RGA vacuum chamber and the filament feedthrough, as shown in Fig. 4(b).

To perform the ESD measurements, one needs a source of electrons with required intensity and energy. The second criterion is that the electrons should bombard the entire sample.

The floating power supply (FUG HCV 1400-1600MOP) allows up to $I_{f}=8$ A current through the filament and biasing up to $6.5 \mathrm{kV}$. The experimental conditions were selected to be $I_{f}=5.0-5.5$ A providing sample bombardment with $E=$ $500 \mathrm{eV}$ electrons with the electron current of $I=120 \mathrm{~mA}$. At these conditions, the total power deposition during ESD measurements (which consists of two parts - filament heat and power of the bombarding electrons) could be as high as $100 \mathrm{~W}$.

The sample tube temperature is maintained with a detachable water-cooled copper clamp jacket, which is installed only during the ESD measurements.

\subsubsection{Measurement procedure}

The test chamber with the sample was vented to dry nitrogen to install the thoriated tungsten filament. After the leak check, all parts of the test chamber were baked to $200{ }^{\circ} \mathrm{C}$ for 24 hours, while the NEG coated tube was kept at approximately $80^{\circ} \mathrm{C}$. At the end of the bakeout the temperature of all parts was reduced to $150{ }^{\circ} \mathrm{C}$, and extractor gauge and RGAs were switched on and degassed. To avoid poisoning, the thoria filament was kept hot $\left(I_{f}=3 \mathrm{~A}\right)$ during the bake out, then shortly after the gauge degassing, it was activated for electron emission by increasing the current to $I_{f}=7$ A for 10 minutes, then it was set to $I_{f}=5-5.5 \mathrm{~A}$ for the duration of the experiment. After that, the temperature of all parts was further reduced to room temperature.

The ESD yield from non-activated NEG coating as a function of electron dose was measured by electron bombarding with $E=500 \mathrm{eV}$ and $I=120 \mathrm{~mA}$ for 5-7 days. After bombardment, the $\mathrm{H}_{2}$ and $\mathrm{CO}$ sticking probabilities and $\mathrm{CO}$ sorption capacity were measured using the same procedure as described in section 3.1.2 by injecting a mixture of the $\mathrm{H}_{2}$ (10\%) and $\mathrm{CO}(90 \%)$.

After that, the experiment was repeated by heating the sample tube to selected activation temperatures in the range from 150 to $300{ }^{\circ} \mathrm{C}$ for 24 hours followed by the initial $\mathrm{H}_{2}$ and $\mathrm{CO}$ sticking probabilities measurements, the ESD measurements and the pumping properties measurements at the end of the experiment. The initial $\mathrm{H}_{2}$ and $\mathrm{CO}$ sticking probabilities were measured by injecting a mixture of the $\mathrm{H}_{2}(10 \%)$ and $\mathrm{CO}(90 \%)$ for 5 minutes at $P=1 \times 10^{-9} \mathrm{mbar}$ (for $\mathrm{H}_{2}$ ) and at $P=5 \times 10^{-8} \mathrm{mbar}$ (for $\mathrm{CO}$ ) to minimise NEG poisoning. The $\mathrm{H}_{2}$ and $\mathrm{CO}$ sticking probabilities and $\mathrm{CO}$ sorption capacity at the end of the ESD bombardment were measured using the same procedure as described in section 3.1.2 by injecting a mixture of the $\mathrm{H}_{2}(10 \%)$ and $\mathrm{CO}(90 \%)$. 


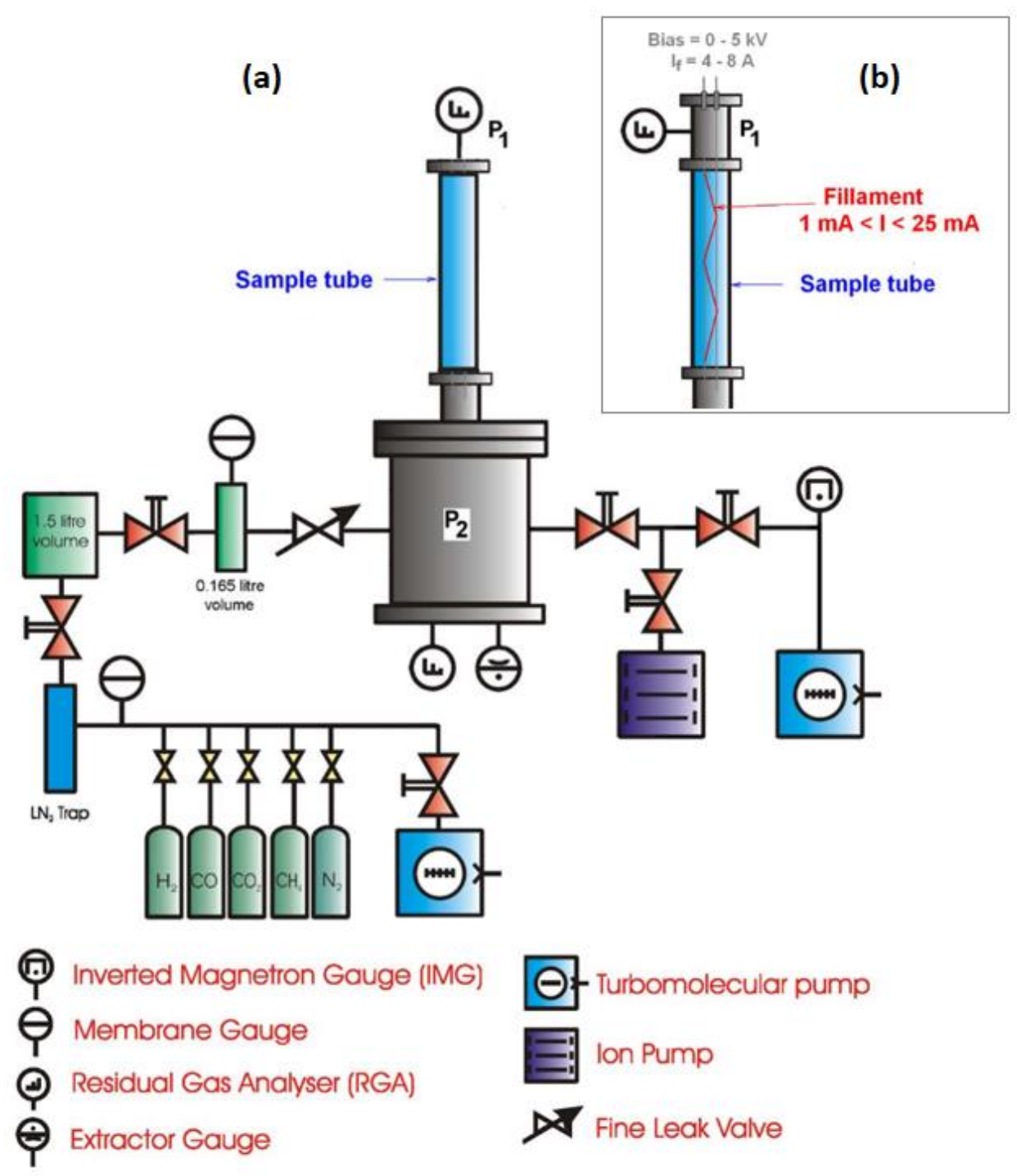

Figures 4: (a) Layout of the vacuum system used for analysing vacuum properties of tubular NEG samples and (b) layout of the top part of the test chamber with a filament along the NEG coated tube for measuring ESD yields from tubular samples

\section{MOLFLOW SIMULATIONS}

To obtain NEG coating sticking probabilities from pressure readings in pumping properties experiments, test particle Monte Carlo (TPMC) modelling of the experimental facility was performed using Molflow software [18]. Vacuum chamber shown in Fig. 4(a) was drawn with CAD software and then imported in Molflow to perform molecular flow simulations. The molecular flow along the NEG coated tube was determined for a discrete number of sticking probabilities ranging from $10^{-4}$ to 1 . Figure 5 shows simulation results for the pressure ratio of the top and bottom RGA partial pressure measurements as a function of sticking probability. These results were used for converting the measured partial pressures to sticking probabilities.

A detailed TPMC study was performed for number of different geometries reported in ref. [19]. An error analysis reported for geometry similar to the one in this paper shows that if partial pressure is measured with accuracy of $20 \%$, the sticking probability error varies in a wide range and depends on sticking probability, thus: $\Delta \alpha / \alpha=5.5$ for $\alpha=10^{-4}$, 
$\Delta \alpha / \alpha=0.7$ for $\alpha=10^{-3}, 0.1 \leq \Delta \alpha / \alpha \leq 0.15$ for $10^{-2} \leq \alpha \leq 0.1$ and $\Delta \alpha / \alpha=0.5$ for $\alpha=1$. That means that in this geometry, the most accurate measurements can be performed for $10^{-2} \leq \alpha \leq 0.1$, while for $\alpha<10^{-3}$ the results are quite inaccurate.

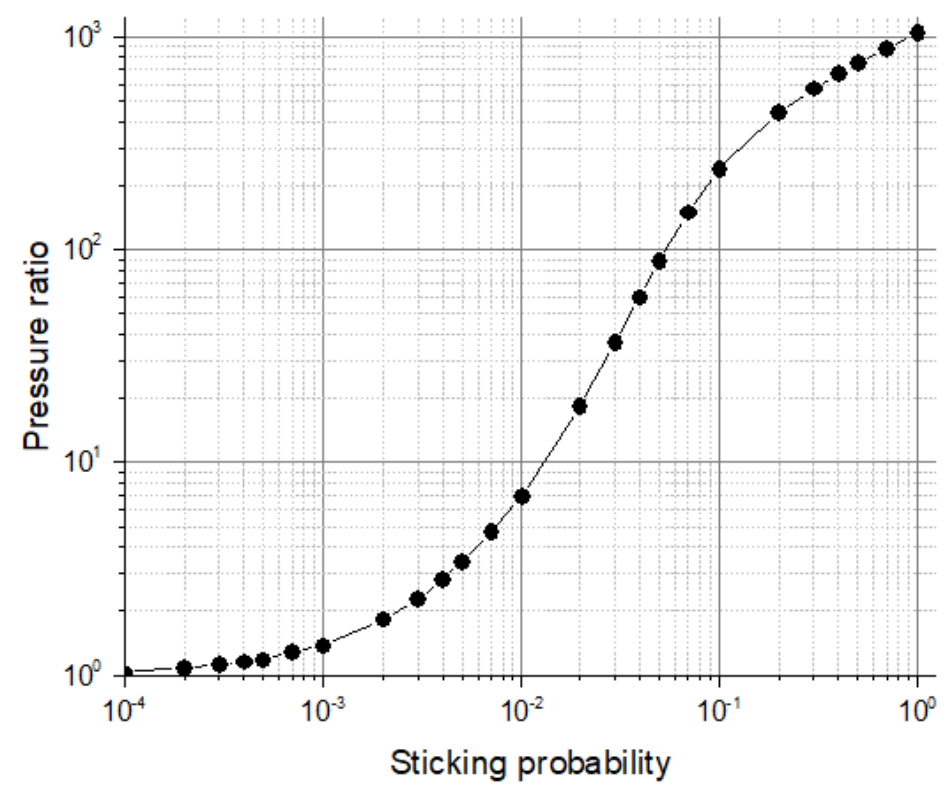

Figure 5: The results of Molflow TPMC simulations for the pressure ratio $\left(\mathrm{P}_{2} / \mathrm{P}_{1}\right)$ as a function of sticking probability of NEG-coated tube with inner diameter of $3.8 \mathrm{~cm}$ and length of $50 \mathrm{~cm}$.

\section{EXPERIMENTAL RESULTS}

\subsection{Pumping properties}

The pumping properties of the NEG coated film were obtained by injecting $\mathrm{H} 2$ or $\mathrm{CO}$ following the procedure described in subsection 4.1.2. For example, the pressure ratios between the bottom and top RGAs for CO injection into the columnar $\mathrm{Zr}$ sample activated to $220{ }^{\circ} \mathrm{C}$ as a function of the amount of injected gas is shown in Fig. 6. The initial sticking probability $\alpha_{0}$ for this activation temperature was determined from the pressure ratio $R_{0}$ at the beginning of injection using the TPMC results shown in Fig. 5. The pumping capacity $C$ is defined in our studies as a number of absorbed molecules per geometric unit area on the NEG surface corresponding to the pressure ratio equal to 10: it is typically higher at the beginning of the gas injection experiments. If the pressure ratio is lower than 10 , the sorption capacity is not defined and considered negligible. 


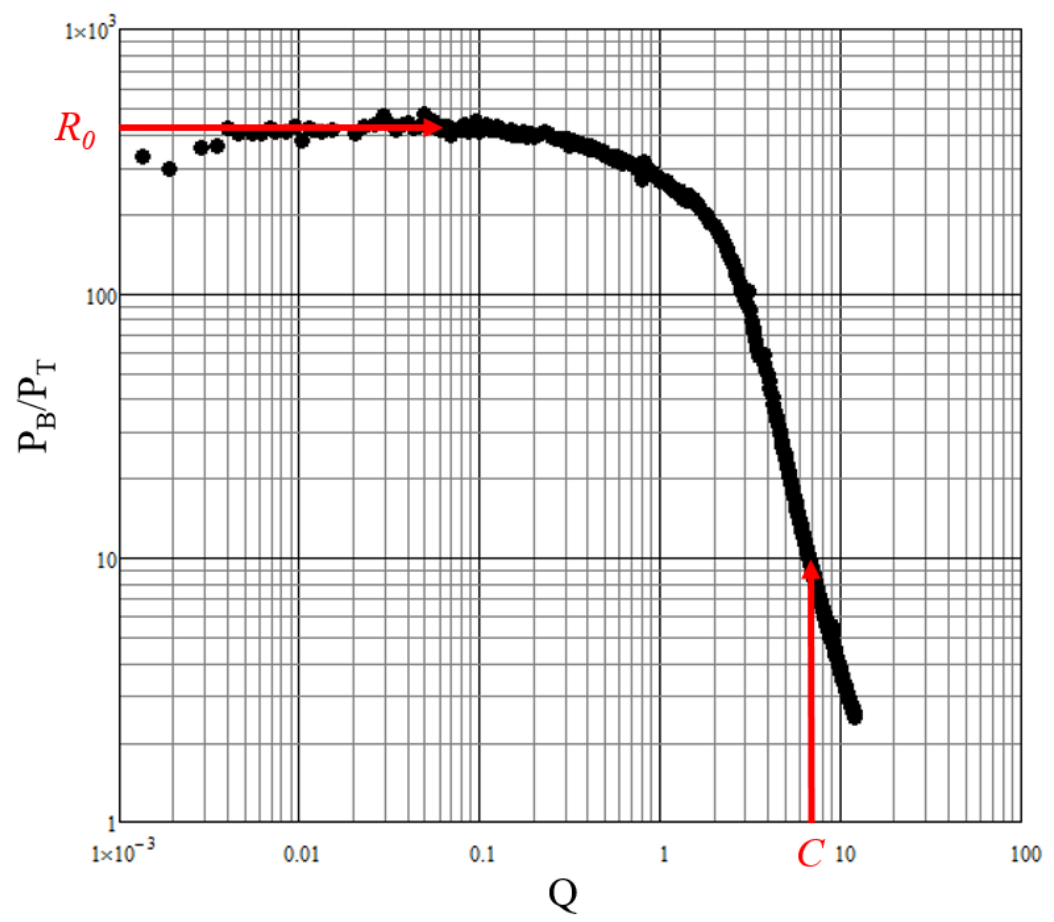

Figure 6: An example of the results for partial pressure ratio as a function of amount of absorbed gas. $R_{0}$ is the initial pressure ratio used to determine an initial sticking probability and $\mathrm{C}$ is sorption capacity defined at $R=10$.

The initial sticking probabilities for $\mathrm{H}_{2}, \mathrm{CO}$ and $\mathrm{CO}_{2}$ were found for both dense and columnar NEG coating activated at temperatures ranging from $T_{s}=140$ to $300{ }^{\circ} \mathrm{C}$; they are shown in Fig. 7. The sticking probability reaches its maximum value when the columnar coating is activated at $160{ }^{\circ} \mathrm{C}$, while the dense coating does not reach the same value even when heated to $T_{s}=250{ }^{\circ} \mathrm{C}$.

Figure 8 shows that full capacity for the $\mathrm{CO}$ gas is reached for the columnar NEG coating activated at $T_{s}=160{ }^{\circ} \mathrm{C}$ while dense film does not provide the same pumping capacity even after activating to $250{ }^{\circ} \mathrm{C}$. 


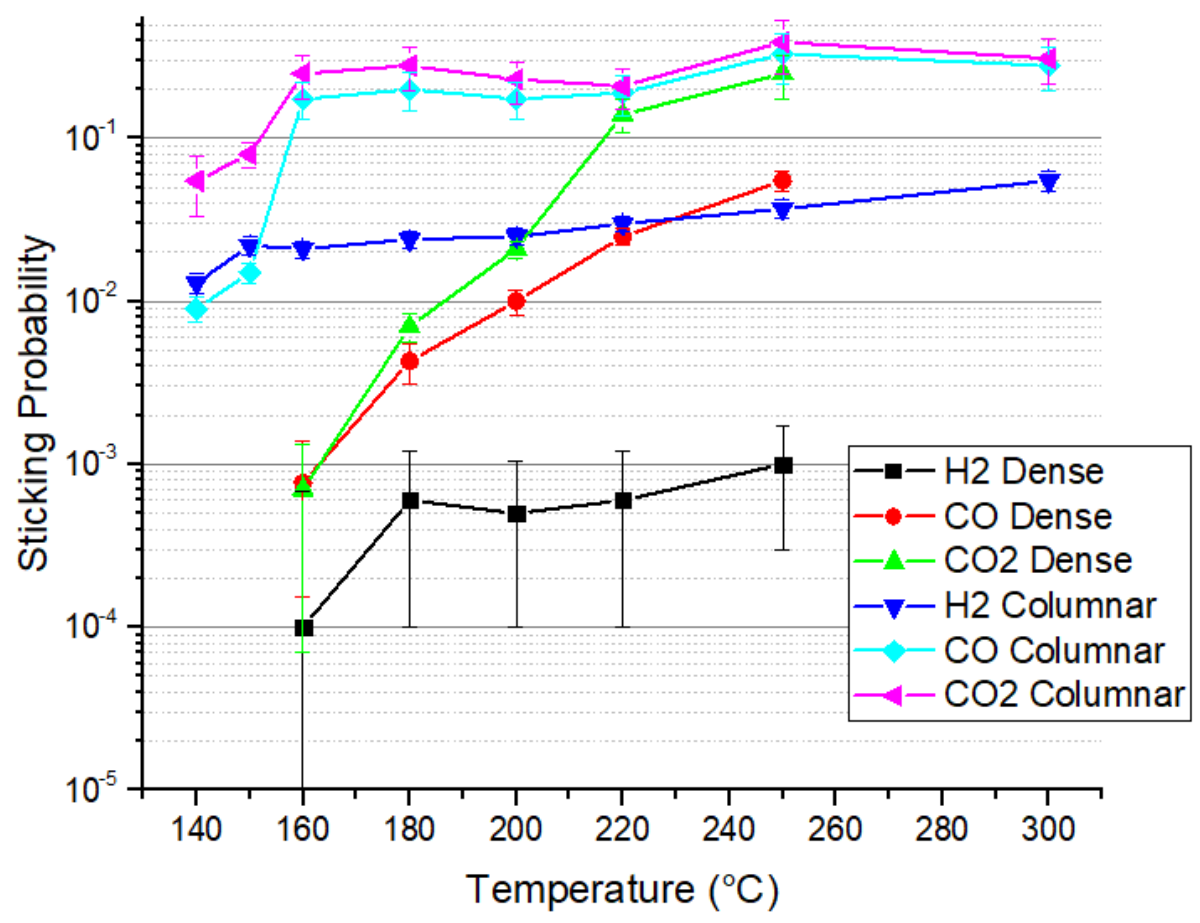

Figure 7: Sticking probabilities for the dense (green) and columnar (red) NEG coating as a function of activation temperature.

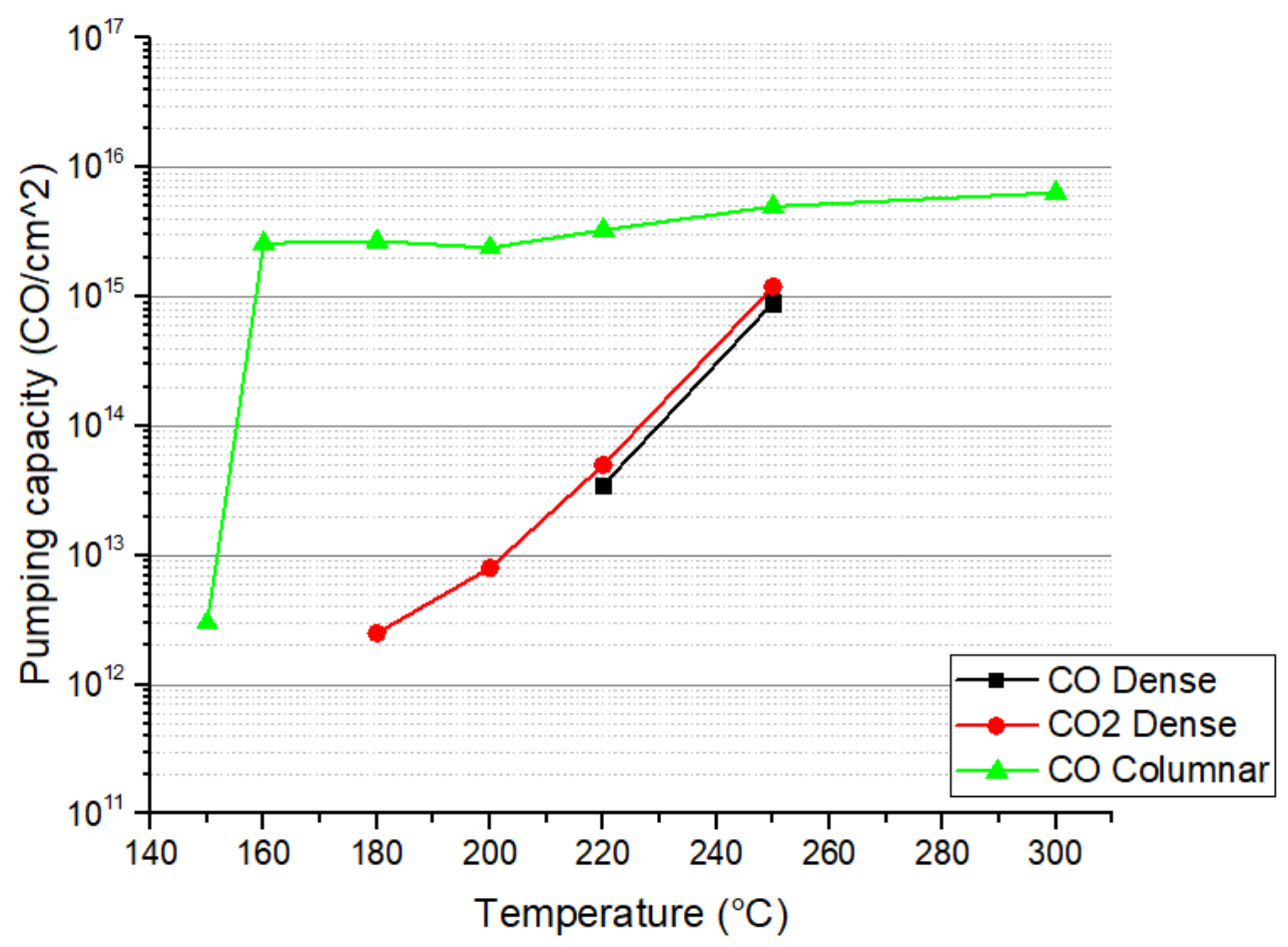

Figure 8: CO pumping capacity of dense (green) and columnar (red) $\mathrm{Zr}$ coating as a function of activation temperature.

\subsection{ESD results}


ESD experiments were performed after a few activations to selected temperatures: non-activated NEG (held at $80{ }^{\circ} \mathrm{C}$ during TC bakeout for $24 \mathrm{~h}$ ), $150{ }^{\circ} \mathrm{C}$ (lowest activation temperature for columnar $\mathrm{Zr}$ ), $180{ }^{\circ} \mathrm{C}$ (commonly applied activation temperature). The activation to higher temperatures had a different procedure for both films: the columnar NEG coating was activated to 200 and $250{ }^{\circ} \mathrm{C}$ (to see ESD after full activation) while the dense coating was activated to 250 and $300{ }^{\circ} \mathrm{C}$ (higher temperatures needed to reach full activation for the dense film, see Fig. 7).

The ESD yields, $\eta$, determined for $\mathrm{H}_{2}, \mathrm{CH}_{4}, \mathrm{CO}$, and $\mathrm{CO}_{2}$, the main gas species observed in a test vacuum chamber, as shown in Figs. 9(a) and 10(a) for dense and Figs. 9(b) and 10(b) for columnar films. The calculations were performed following the procedure described in [10]. The results are presented in two forms - Fig. 9 shows the ESD yields as a function of electron dose from the dense and the columnar NEG coated samples and Figs. 10 shows ESD yields as a function of amount of desorbed gas from the samples. The amount of gas is defined in terms of monolayer $(\mathrm{ML})$, where monolayer is given as the amount of gas molecules per unit geometrical surface area: $\mathrm{ML}=5 \times 10^{14}$ $\mathrm{CO} / \mathrm{cm}^{2}$.

\subsubsection{ESD yields for $\mathrm{H}_{2}$}

5.2.1.1 $T_{s}=80^{\circ} \mathrm{C}$

The ESD behaviour as a function of dose and the temperature is different for the dense and columnar films. For nonactivated NEG $\left(T_{s}=80^{\circ} \mathrm{C}\right)$ the ESD yields from the dense and columnar films are comparable within a factor of two.

\subsubsection{2 $T_{s}=150{ }^{\circ} \mathrm{C}$}

Baking the sample tube to $T_{s}=150{ }^{\circ} \mathrm{C}$ reduces the initial $\eta_{\mathrm{H} 2}$ down to $10^{-4} \mathrm{H}_{2} / \mathrm{e}^{-}$for the dense film while for the columnar it is only $\eta_{\mathrm{H} 2}=4 \times 10^{-3} \mathrm{H}_{2} / \mathrm{e}^{-}$. Activation to $150{ }^{\circ} \mathrm{C}$ significantly reduces ESD from the dense NEG but does not activate it, while for the columnar film it provides the pumping properties, but is less efficient for reducing ESD in comparison to the dense one.

\subsubsection{3 $T_{s}=180{ }^{\circ} \mathrm{C}$}

Baking the sample to the higher temperature of $T_{s}=180{ }^{\circ} \mathrm{C}$ does not reduce the initial ESD from the dense film, but conditioning is more efficient. After reaching a dose of $10^{23} \mathrm{e}^{-} / \mathrm{m}^{2}$, the dense film demonstrates $\eta_{\mathrm{H} 2}<10^{-7} \mathrm{H}_{2} / \mathrm{e}^{-}$. One should also note that after activation to this temperature, the dense coating shows some pumping properties. In comparison, the columnar film shows ESD reduced down to $\eta_{\mathrm{H} 2} \approx 10^{-4} \mathrm{H}_{2} / \mathrm{e}^{-}$. The conditioning with dose is not as efficient: after reaching a dose of $10^{23} \mathrm{e}^{-} / \mathrm{m}^{2}$, the columnar film demonstrates $\eta_{\mathrm{H} 2}=10^{-5} \mathrm{H}_{2} / \mathrm{e}^{-}$.

\subsubsection{4 $T_{s}=250{ }^{\circ} \mathrm{C}$}

The dense and columnar samples can also be compared after heating to $T_{s}=250{ }^{\circ} \mathrm{C}$. The initial $\eta_{\mathrm{H} 2}$ for the dense coating is comparable to the one after activation to $T_{s}=180{ }^{\circ} \mathrm{C}$; however, for larger doses, the condition becomes less efficient, reaching the minimum ESD value $\eta_{\mathrm{H} 2}=7.5 \times 10^{-7} \mathrm{H}_{2} / \mathrm{e}^{-}$at dose $\mathrm{D}=2.5 \times 10^{23} \mathrm{e}^{-} / \mathrm{m}^{2}$, then increasing with dose reaching $\eta_{\mathrm{H} 2}=3 \times 10^{-6} \mathrm{H}_{2} / \mathrm{e}^{-}$at the end of the bombardment with $\mathrm{D}=4 \times 10^{24} \mathrm{e}^{-} / \mathrm{m}^{2}$. This behaviour of ESD yield as a function of dose has been earlier observed with TiZrHfV samples [11], where the ESD yield does not reduce continuously with the dose, but instead has a local minimum. The columnar film initial ESD is higher by a factor of 2 ; however, conditioning is much slower, thus it becomes a factor of 10 higher at $\mathrm{D}=10^{22} \mathrm{e}^{-} / \mathrm{m}^{2}$. The minimum ESD value 
$\eta_{\mathrm{H} 2}=1.2 \mathrm{e}-5 \mathrm{H}_{2} / \mathrm{e}^{-}$is reached at $\mathrm{D}=10^{24} \mathrm{e}^{-} / \mathrm{m}^{2}$, then slowly increasing with dose reaching $\eta_{\mathrm{H} 2}=1.3 \mathrm{e}-5 \mathrm{H}_{2} / \mathrm{e}^{-}$at the end of the bombardment with $\mathrm{D}=4.5 \times 10^{24} \mathrm{e}^{-1} / \mathrm{m}^{2}$.

From these results one can conclude that the ESD from the dense film activated at $T_{s} \geq 150{ }^{\circ} \mathrm{C}$ provide lower ESD yields.

\subsubsection{Comparison of the ESD results for $\mathrm{Zr}$ and TiZrHfV}

These results for $\mathrm{H}_{2}$ could be compared to the ones obtained from the dense and columnar TiZrHfV samples [11].

The ESD for non-activated NEG $\left(T_{s}=80^{\circ} \mathrm{C}\right)$ the ESD yields from the dense $\mathrm{Zr}$ film are higher by a factor of two. For the columnar film, $\mathrm{Zr}$ film provides $\eta_{\mathrm{H} 2}$ that is a factor of ten higher than the one from TiZrHfV film.

For $T_{s}=150{ }^{\circ} \mathrm{C}$, the dense $\mathrm{Zr}$ film provides results which are lower by a factor of 3-10, while for the columnar film it is the opposite - the TiZrHfV film ESD is a factor of 10-14 lower.

For $T_{s}=180{ }^{\circ} \mathrm{C}$, the ESD yield from the dense $\mathrm{Zr}$ film is 2-30 times lower for doses up to $\mathrm{D}=3 \times 10^{22} \mathrm{e}^{-} / \mathrm{m}^{2}$; for higher does the difference is even more noticeable because the ESD yield for TiZrHfV is increasing with large dose. One should note that behaviour of $\eta_{\mathrm{H} 2}$ for TiZrHfV activated at $T_{s}=180{ }^{\circ} \mathrm{C}$ is quite comparable with one for $\mathrm{Zr}$ activated at $T_{s}=250{ }^{\circ} \mathrm{C}$. The initial yield from the columnar $\mathrm{Zr}$ film is in the range of $10^{-4} \mathrm{H}_{2} / \mathrm{e}^{-}$and slowly goes down to $1.3 \times 10^{-5} \mathrm{H}_{2} / \mathrm{e}^{-}$at the end of the bombardment. The initial ESD yield from the columnar TiZrHfV film is $4 \times 10^{-4} \mathrm{H}_{2} / \mathrm{e}^{-}$, reaching its minimum of $1.3 \times 10^{-5}$ at $\mathrm{D}=3 \times 10^{22} \mathrm{e}^{-} / \mathrm{m}^{2}$, and then reaching local maximum of $3 \times 10^{-5} \mathrm{H}_{2} / \mathrm{e}^{-}$at $\mathrm{D}=6 \times 10^{23}$ $\mathrm{e}^{-} / \mathrm{m}^{2}$.

For $T_{s}=250{ }^{\circ} \mathrm{C}$, ESD yields from both dense films are comparable up to the dose of $\mathrm{D}=10^{22} \mathrm{e} / \mathrm{m}^{2}$; but TiZrHfV reaches a minimum $3 \times 10^{-6} \mathrm{H}_{2} / \mathrm{e}^{-}$at $3 \times 10^{22} \mathrm{e}^{-} / \mathrm{m}^{2}$ while the yield from $\mathrm{Zr}$ film continues to go down to its minimum of $8 \times 10^{-7} \mathrm{H}_{2} / \mathrm{e}^{-}$reached at $\mathrm{D}=2.5 \times 10^{23} \mathrm{e}^{-} / \mathrm{m}^{2}$. Initial yields from both coatings are comparable; however, yield from TiZrHfV reaches its minimum of $1.8 \times 10^{-5} \mathrm{H}_{2} / \mathrm{e}^{-}$at $\mathrm{D}=3.5 \times 10^{21} \mathrm{e}^{-} / \mathrm{m}^{2}$, followed by an increase to $8 \times 10^{-5} \mathrm{H}_{2} / \mathrm{e}^{-}$at $2 \times 10^{23}$ $\mathrm{e}^{-} / \mathrm{m}^{2}$; while $\mathrm{Zr}$ film steadily decreases in the whole range of measurements to the value of $1.3 \times 10^{-5} \mathrm{H}_{2} / \mathrm{e}^{-}$.

From these results, one can see that the $\mathrm{Zr}$ films provides the lowest ESD values in the whole range of doses for films activated at $T_{s} \geq 150^{\circ} \mathrm{C}$. Furthermore, a local minimum in ESD yield from the $\mathrm{Zr}$ films is either not present (for $T_{s}=80$, 150 and $180^{\circ} \mathrm{C}$ ) or appears at much higher (1-2 orders of magnitude) doses than for TiZrHfV.

The difference between TiZrHfV and $\mathrm{Zr}$ dense films could be related to chemical composition since both films have the same structure. However, for the TiZrHfV and Zr columnar films, the properties could also be influenced by differences in structure: the deposition parameters control how densely packed the columns on the film surface are, which consequently modifies the active surface area over a potentially wide range.

\subsubsection{ESD yields for $\mathrm{CH} 4$}

For the samples baked to $80^{\circ} \mathrm{C}$ the initial ESD yield $\eta_{\mathrm{CH} 4}$ from the dense film is four times higher than the one from the columnar film; however, $\eta_{\mathrm{CH} 4}$ from the dense coating reduces by four orders of magnitude while $\eta_{\mathrm{CH} 4}$ reduces by three orders of magnitude only.

The initial $\eta_{\mathrm{CH} 4}$ are quite similar for the dense film after activations to 150,180 and $250{ }^{\circ} \mathrm{C}$ and are comparable to the $\mathrm{CH}_{4}$ ESD yield from the columnar film after activation to $150{ }^{\circ} \mathrm{C}$. The initial yields for the columnar film after activations to $T_{s}=180$ and $250{ }^{\circ} \mathrm{C}$ are lower by a factor of 3 and 10 , respectively; they demonstrate stronger conditioning effect with a dose. 
In comparison with TiZrHfV films, $\mathrm{Zr}$ demonstrated higher $\eta_{\mathrm{CH} 4}$ for both morphologies. The yields with accumulated dose of $D=10^{23} \mathrm{e}^{-} / \mathrm{m}^{2}$ are an order of magnitude higher for the dense $\mathrm{Zr}$ film and 1-2 orders of magnitude higher for the columnar Zr film.

\subsubsection{ESD yields for CO}

The initial ESD yield $\eta_{\mathrm{CO}}$ from the non-activated dense film is higher by a factor of two than the one from the columnar film; the $\mathrm{CO}$ yield from the columnar film remains lower throughout the entire bombardment.

While initial $\eta_{\mathrm{CO}}$ from the columnar film after activations to 150,180 and $200{ }^{\circ} \mathrm{C}$ are quite similar, however, the lowest ESD yields is achieved after activation to $250{ }^{\circ} \mathrm{C}$. The lowest ESD yields for the dense film are achieved after activation to $180{ }^{\circ} \mathrm{C}$, however, initial yields are 3-4 orders of magnitude higher than the ones from the columnar film. The dense coating shows yields lower by a factor of ten at the end of bombardment for all activation temperatures higher than $80^{\circ} \mathrm{C}$.

Both initial and final yields from the dense coating are better for TiZrHfV film by around an order of magnitude, while the results from the columnar films are more comparable. The TiZrHfV shows lower yields by a factor of 3-5 only.

\subsubsection{ESD yields for $\mathrm{CO}_{2}$}

The initial ESD yield $\eta_{\mathrm{CO} 2}$ from the non-activated dense film is lower by approximately an order of magnitude than the one from the columnar film; the conditioning is more efficient with the columnar film.

Activation to higher temperatures for the columnar film results in ESD yields varying from initial values of approximately $10^{-4} \mathrm{CO}_{2} / \mathrm{e}^{-}$to final values of approximately $10^{-6} \mathrm{CO}_{2} / \mathrm{e}^{-}$at $D \approx 10^{25} \mathrm{e}^{-} / \mathrm{m}^{2}$. For the dense film, the lowest ESD was obtained after activation to 150 and $180{ }^{\circ} \mathrm{C}$, varying from initial values of approximately $10^{-5} \mathrm{CO}_{2} / \mathrm{e}^{-}$to final values of approximately $10^{-8} \mathrm{CO}_{2} / \mathrm{e}^{-}$at $D \approx 4 \times 10^{24} \mathrm{e}^{-} / \mathrm{m}^{2}$.

In comparison to TiZrHfV, these ESD results for $\mathrm{CO}_{2}$ are lower for the dense film and higher for the columnar one. However, due to a high $\mathrm{CO}_{2}$ sticking probability the sensitivity of ESD yield measurements is quite low; therefore, it is difficult to determine the yields accurately. 
a) Dense

$\mathrm{H}_{2}$

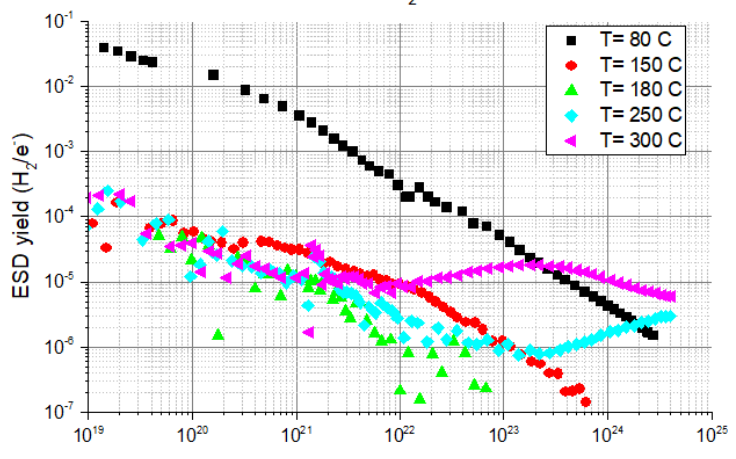

$\mathrm{CH}_{4}$

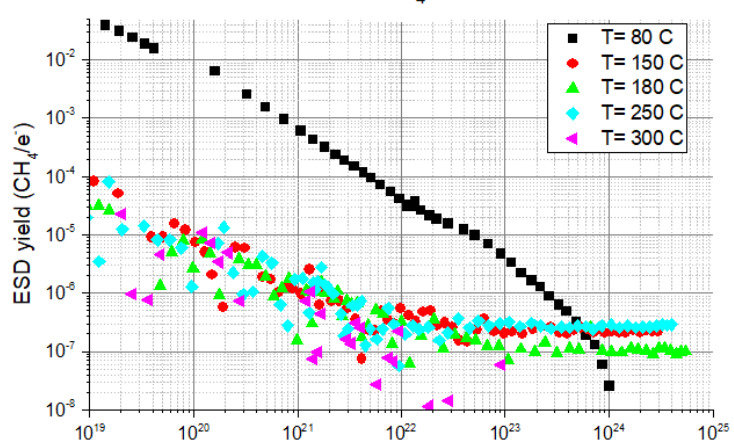

$\mathrm{CO}$

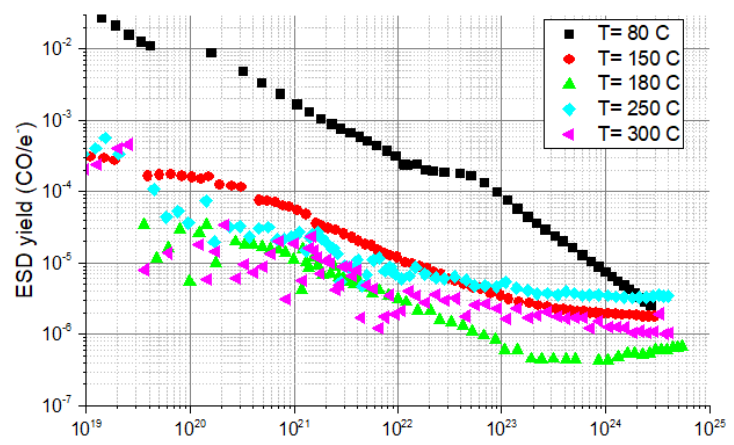

$\mathrm{CO}_{2}$

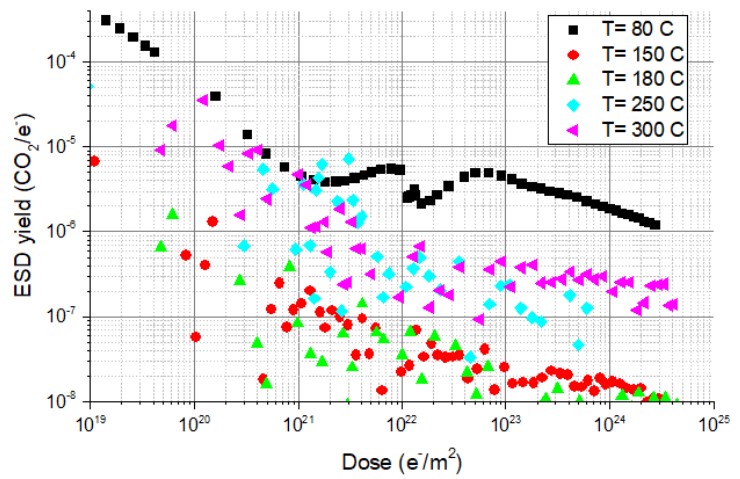

b) Columnar

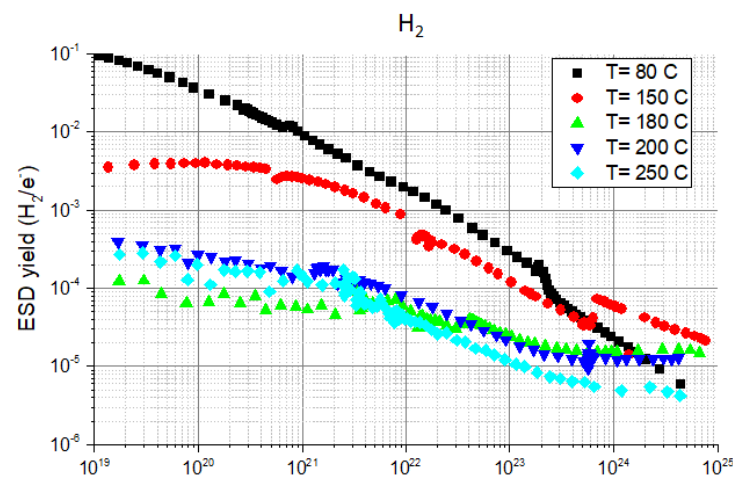

$\mathrm{CH}_{4}$

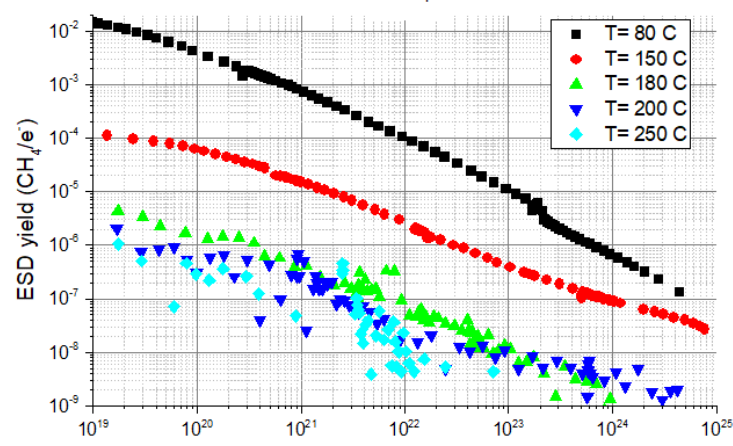

CO

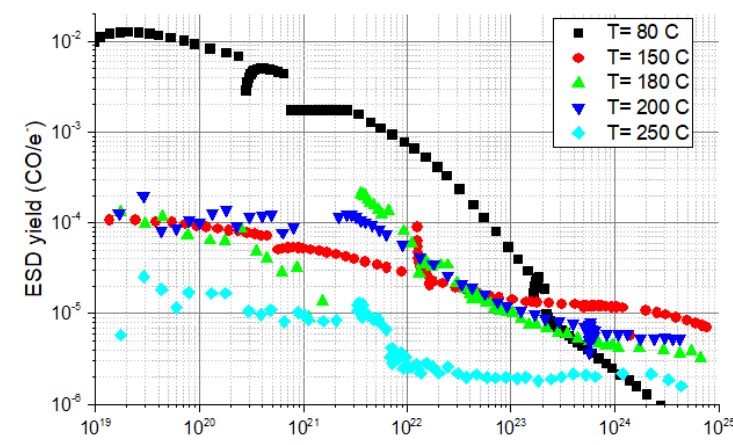

$\mathrm{CO}_{2}$

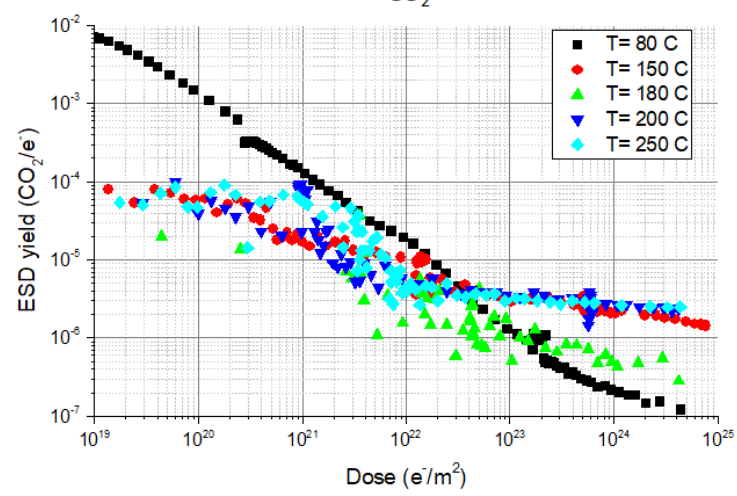

Figure 9: ESD yields as a function of electron dose from a) dense and b) columnar NEG samples. 
a) Dense

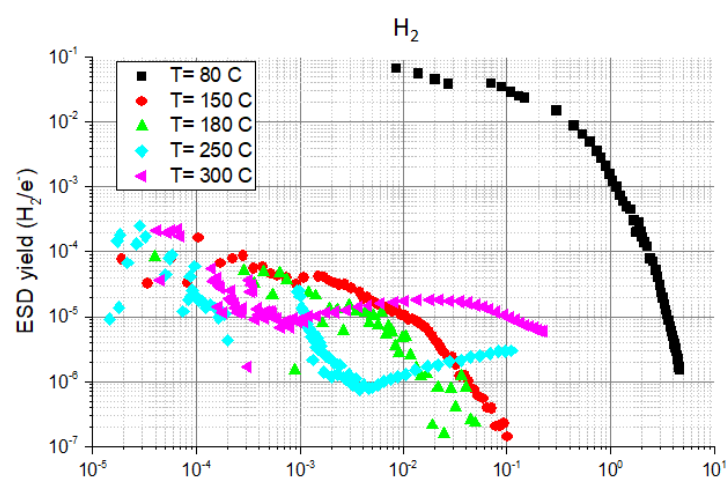

$\mathrm{CH}_{4}$

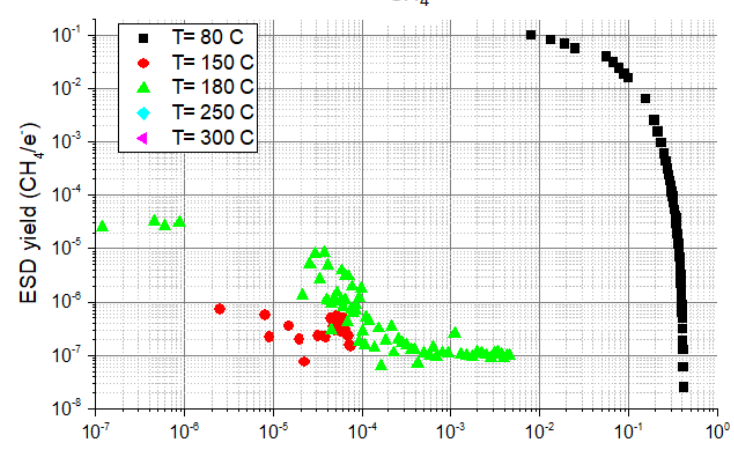

$\mathrm{CO}$

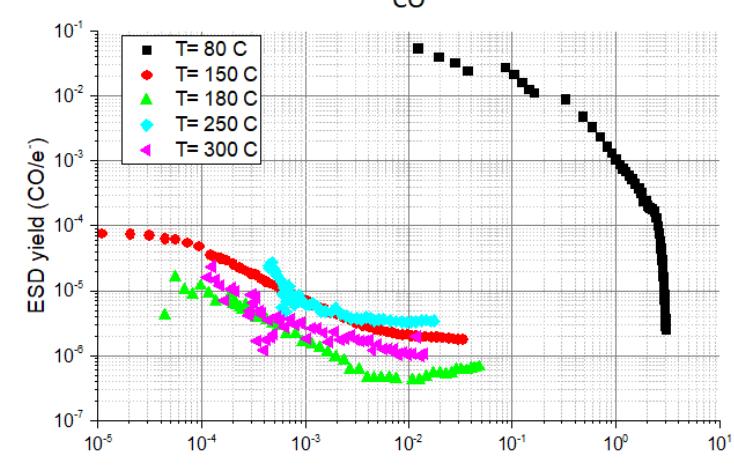

$\mathrm{CO}_{2}$

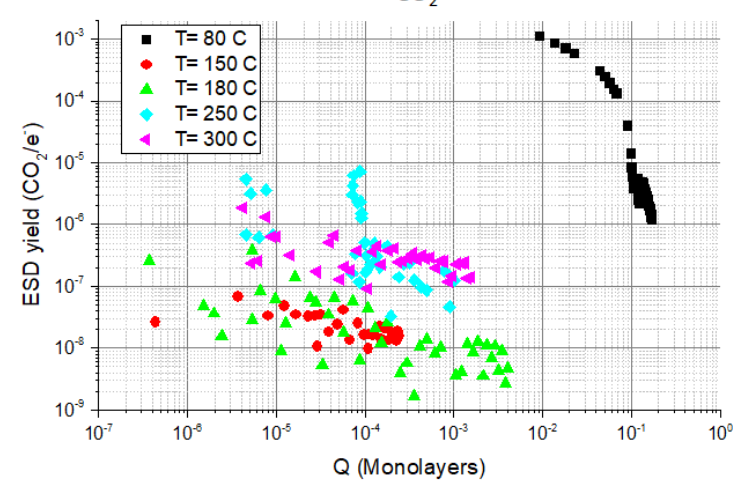

b) Columnar

$\mathrm{H}_{2}$

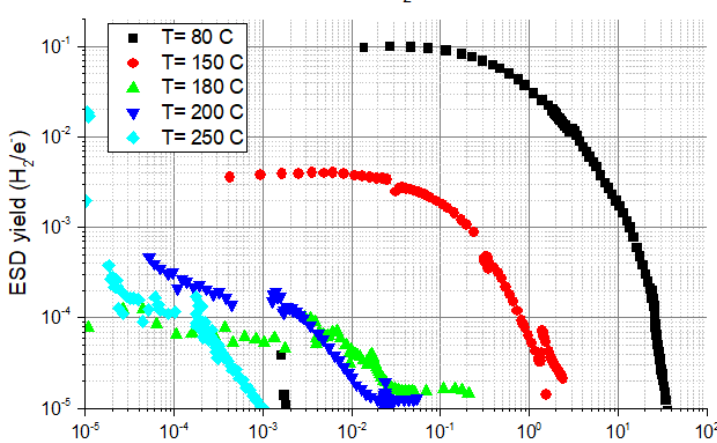

$\mathrm{CH}_{4}$

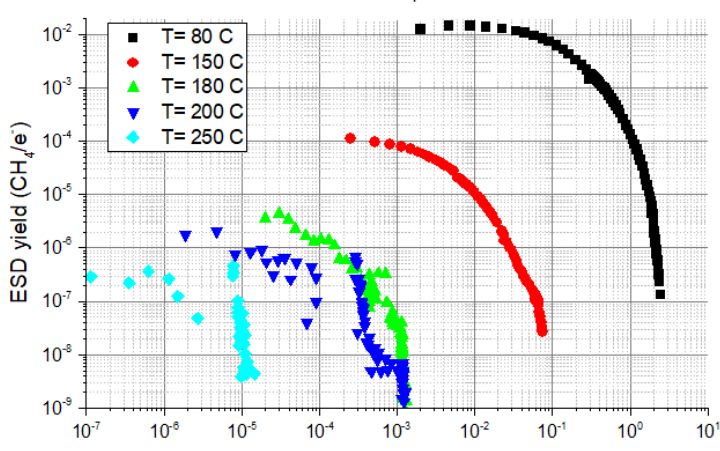

CO

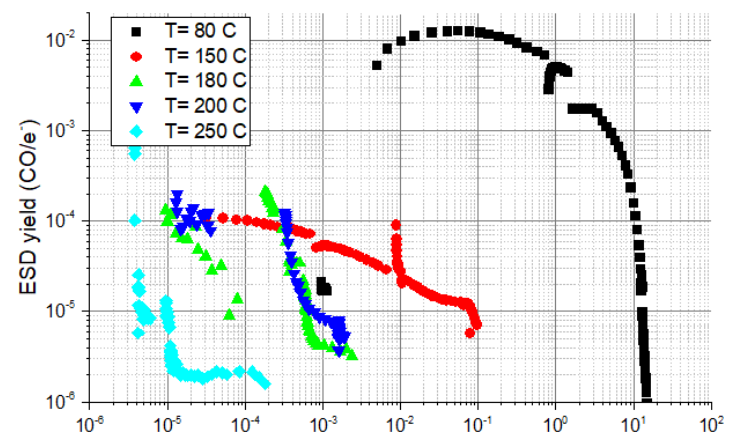

$\mathrm{CO}_{2}$

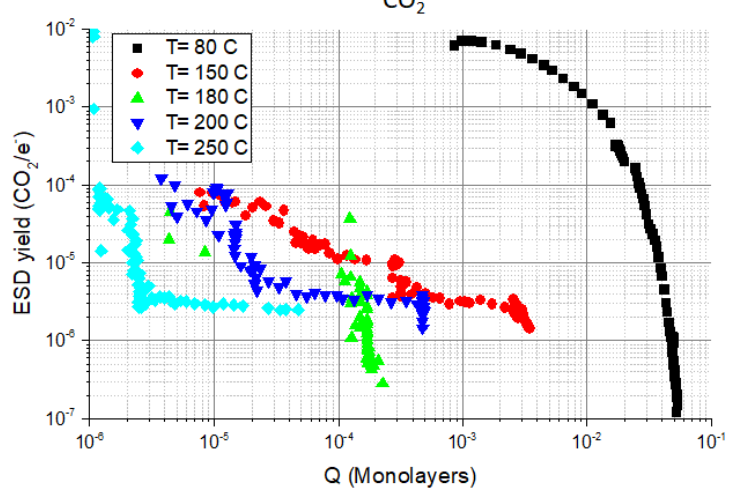

Figure 10: ESD yields as a function of amount of desorbed gas from a) dense and b) columnar NEG samples.

Table 2: ESD yields corresponding to electron dose of $2.7 \times 10^{24} \mathrm{e}^{-} / \mathrm{m}^{2}$. 


\begin{tabular}{|l|c|c|c|c|c|c|c|c|}
\hline & \multicolumn{9}{|c|}{$\eta($ molecules/e $)$} \\
\hline & \multicolumn{2}{|c|}{$\mathrm{H}_{2}$} & \multicolumn{2}{c|}{$\mathrm{CH}_{4}$} & \multicolumn{2}{c|}{$\mathrm{CO}$} & \multicolumn{2}{c|}{$\mathrm{CO}_{2}$} \\
\hline $\mathrm{T}\left({ }^{\circ} \mathrm{C}\right)$ & dense & col & dense & col & dense & col & dense & col \\
\hline 80 & $1.5 \times 10^{-6}$ & $1 \times 10^{-5}$ & & $2 \times 10^{-7}$ & $2.5 \times 10^{-6}$ & $2 \times 10^{-6}$ & $1 \times 10^{-6}$ & $2 \times 10^{-7}$ \\
\hline 150 & $1 \times 10^{-7}$ & $3 \times 10^{-5}$ & $2 \times 10^{-7}$ & $5 \times 10^{-8}$ & $2 \times 10^{-6}$ & $1 \times 10^{-5}$ & $1 \times 10^{-8}$ & $2 \times 10^{-6}$ \\
\hline 180 & $1 \times 10^{-7}$ & $1.6 \times 10^{-5}$ & $1 \times 10^{-7}$ & $1 \times 10^{-9}$ & $6 \times 10^{-7}$ & $4 \times 10^{-6}$ & $1 \times 10^{-8}$ & $5 \times 10^{-7}$ \\
\hline 200 & & $1.3 \times 10^{-6}$ & & $2 \times 10^{-9}$ & & $6 \times 10^{-6}$ & & $2.4 \times 10^{-6}$ \\
\hline 250 & $3 \times 10^{-6}$ & $6 \times 10^{-6}$ & $3 \times 10^{-7}$ & - & $3.5 \times 10^{-6}$ & $2 \times 10^{-6}$ & & $2.5 \times 10^{-6}$ \\
\hline 300 & $6 \times 10^{-6}$ & & - & & $1 \times 10^{-6}$ & & $2 \times 10^{-7}$ & \\
\hline
\end{tabular}

Table 3: Amount of desorbed gas corresponding to electron dose of $2.7 \times 10^{24} \mathrm{e}^{-} / \mathrm{m}^{2}$.

\begin{tabular}{|l|c|c|c|c|c|c|c|c|}
\hline & \multicolumn{9}{|c|}{ Amount of desorbed gas (monolayers) } \\
\hline & \multicolumn{2}{|c|}{$\mathrm{H}_{2}$} & \multicolumn{2}{c|}{$\mathrm{CH}_{4}$} & \multicolumn{2}{c|}{$\mathrm{CO}$} & \multicolumn{2}{c|}{$\mathrm{CO}_{2}$} \\
\hline $\mathrm{T}\left({ }^{\circ} \mathrm{C}\right)$ & dense & col & dense & col & dense & col & dense & col \\
\hline 80 & 4.6 & 36 & 0.42 & 2.4 & 3.0 & 15 & 0.17 & 0.05 \\
\hline 150 & 0.28 & 1.8 & $7 \times 10^{-5}$ & 0.068 & 0.033 & 0.083 & $2.4 \times 10^{-4}$ & $3.2 \times 10^{-3}$ \\
\hline 180 & 0.28 & 0.11 & $2.8 \times 10^{-3}$ & $1.6 \times 10^{-3}$ & 0.026 & $1.3 \times 10^{-3}$ & $2.4 \times 10^{-3}$ & $2.1 \times 10^{-4}$ \\
\hline 200 & & 0.042 & & $1.2 \times 10^{-3}$ & & $1.8 \times 10^{-3}$ & & $4.9 \times 10^{-4}$ \\
\hline 250 & 0.06 & $6 \times 10^{-3}$ & - & $2.5 \times 10^{-3}$ & 0.013 & $1.3 \times 10^{-4}$ & $3.5 \times 10^{-3}$ & $3.5 \times 10^{-5}$ \\
\hline 300 & 0.17 & & $1 \times 10^{-3}$ & & 0.01 & & $1.1 \times 10^{-3}$ & \\
\hline
\end{tabular}

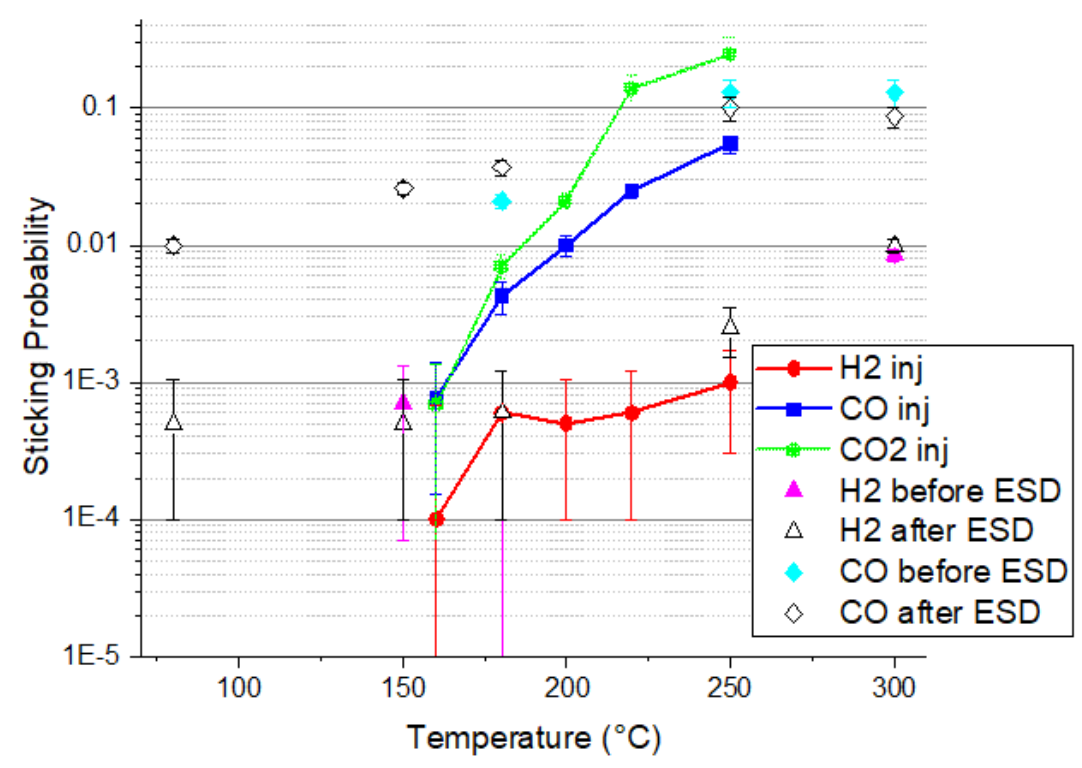

Figure 11: Sticking probabilities as a function of activation temperature during injection experiments in comparison with sticking probabilities before and after ESD for the dense $\mathrm{Zr}$ sample. 


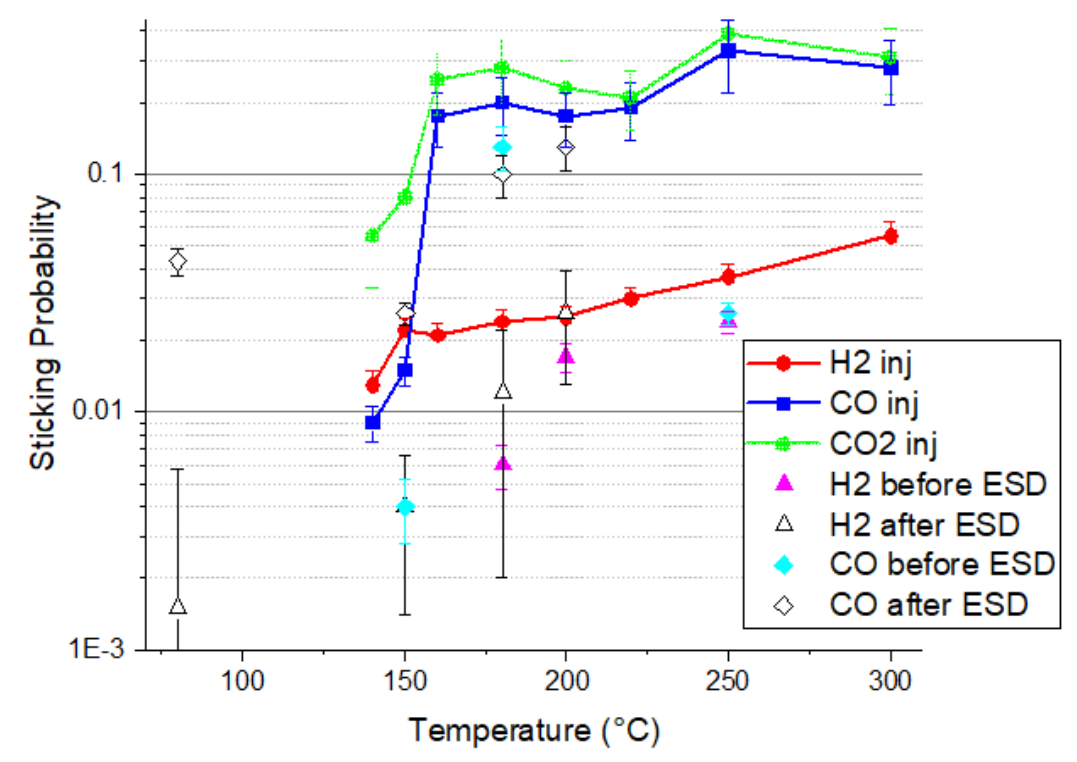

Figure 12: Sticking probabilities as a function of activation temperature during injection experiments in comparison with sticking probabilities before and after ESD for the columnar Zr sample.

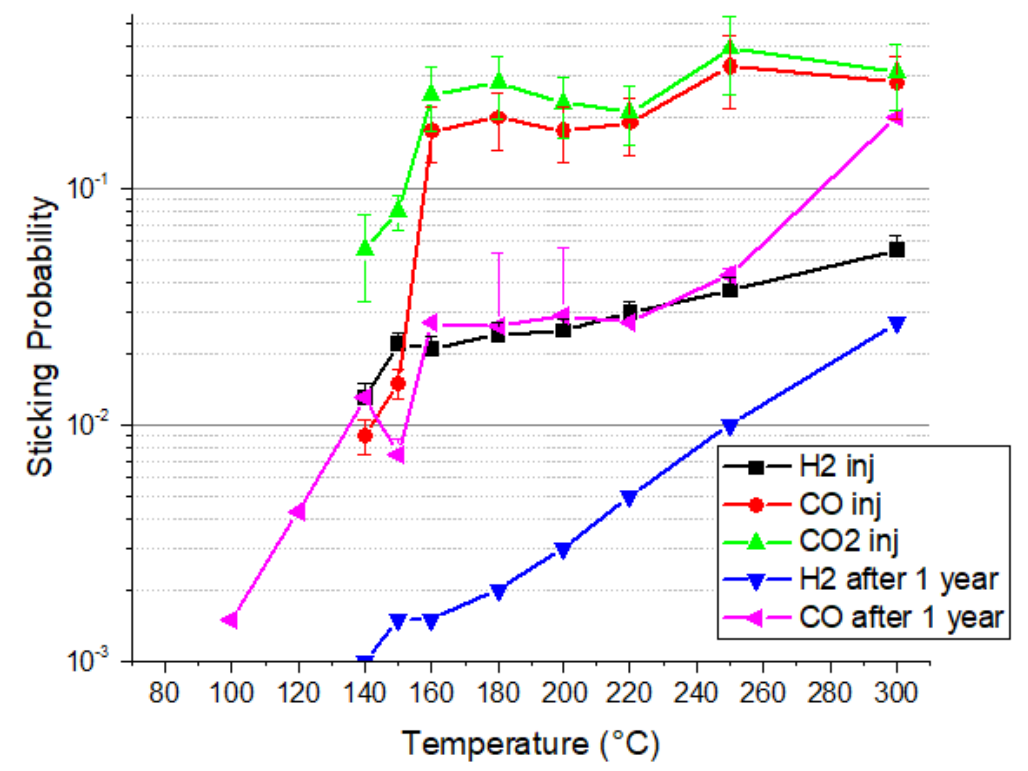

Figure 13: Sticking probabilities as a function of activation temperature measured with the columnar $\mathrm{Zr}$ sample after an exposure to air for one year in comparison with original sticking probabilities. 


\section{DISCUSSION}

\subsection{Pumping properties}

The initial sticking probabilities (shown in fig, 7) and sorption capacity (shown in Fig. 8) of dense $\mathrm{Zr}$ are lower than columnar $\mathrm{Zr}$ over the whole range of activation temperatures measured.

The lowest baking temperature for NEG activation temperature applied to the columnar film was $140{ }^{\circ} \mathrm{C}$. Even at such a low temperature some pumping speed was observed. In comparison to the sticking probabilities obtained after activation to $250{ }^{\circ} \mathrm{C}$, the initial sticking probabilities after activation to $140{ }^{\circ} \mathrm{C}$ are $35 \%$ for $\mathrm{H}_{2}, 3 \%$ for $\mathrm{CO}$ and $14 \%$ for $\mathrm{CO}_{2}$. Activation to $160{ }^{\circ} \mathrm{C}$ provides pumping properties which are not very different from the ones after activation to $250{ }^{\circ} \mathrm{C}$. The absolute values of sticking probabilities of columnar Zr NEG coating are quite comparable to the results obtained earlier for the quaternary Ti-Zr-Hf-V NEG coating [8]. In terms of sorption capacity, it is negligible for activation temperatures of 140 and $150{ }^{\circ} \mathrm{C}$, but after activation to $160{ }^{\circ} \mathrm{C}$, it reaches $50 \%$ of its full activation capacity in reference $10 \mathrm{ML}$ after activation to $250{ }^{\circ} \mathrm{C}$. This sorption capacity is even greater than for the best quaternary film measured earlier.

The dense film has shown some pumping properties after activation to $160^{\circ} \mathrm{C}$ but two orders of magnitude lower than ones for the columnar film. The sticking probability of $\mathrm{CO}$ and $\mathrm{CO}_{2}$ for dense $\mathrm{Zr}$ increases with temperature but does not reach the value for the columnar $\mathrm{Zr}$ film at temperatures up to $250{ }^{\circ} \mathrm{C}$. Even after activation to $250{ }^{\circ} \mathrm{C}$ only $\mathrm{CO}_{2}$ sticking probability is comparable to the columnar film. The $\mathrm{CO}$ sticking probability is lower by a factor of six and $\mathrm{H}_{2}$ sticking probability is lower by a factor of 30 . The sorption capacity of the dense film is negligible after activation below $200{ }^{\circ} \mathrm{C}$. After activation to 220 and $250{ }^{\circ} \mathrm{C}$, the $\mathrm{CO}$ sorption capacity is about a factor of 6 lower than the columnar one. However, its absolute value is about a monolayer, which is quite good for a NEG film. Thus, pure $\mathrm{Zr}$ dense film pumping properties are not as good as the ones for the columnar film; however, after activation to $\geq 180{ }^{\circ} \mathrm{C}$ it provides pumping properties which could be sufficient for applying in an accelerator vacuum chamber.

Let us consider why the pumping properties of the dense and columnar films are so different. The significant difference in behaviour of dense and columnar NEG films can be explained by morphological and structural differences in both films. The pumping properties of the dense $\mathrm{Zr}$ film likely represent the intrinsic properties of $\mathrm{Zr}$ on a geometrically flat surface. It is a reasonable assumption that the intrinsic sticking coefficient of the $\mathrm{Zr}$ surface is the same for both structures. However, the columnar structure consists of long pumping channels (similar to Faraday cups) oriented perpendicular to the surface. The capture efficiency of such channels depends on both: the intrinsic sticking coefficient of $\mathrm{Zr}$ wall and the high aspect ratio of the length of the pumping channel to its cross-section. This explains high sticking probability and high pumping capacity of the columnar structure, defined by greater physical surface area available for pumping. This also demonstrates the difference between the sticking coefficient (intrinsic property of the material) and sticking probability (which also depends on the film morphology).

Thus, one can conclude that pure $\mathrm{Zr}$ columnar film is a good alternative to Ti-Zr- $\mathrm{V}$ and Ti-Zr-Hf- $\mathrm{V}$ columnar films because it provides similar or even better pumping properties at much lower cost. Even the dense $\mathrm{Zr}$ film provides pumping properties in the range of activation temperatures of 180 to $250{ }^{\circ} \mathrm{C}$. The other advantage of the single metal target is that it enables deposition onto a vacuum chamber with a small inner aperture. Single wire targets have a diameter of $1 \mathrm{~mm}$ or less, which can be placed more easily and can guarantee no electrical contact with the vacuum chamber walls. In comparison to this, twisted wire targets, such as $\mathrm{Ti}, \mathrm{Zr}$ and $\mathrm{V}$, take up more space and cannot provide 
a uniform coating. The uniformity of the coating is not an issue for the alloy targets, but they are usually as wide as the twisted wires, $3 \mathrm{~mm}$ in diameter; moreover, there are not many suppliers of alloy targets in the form of a long rod.

All the pumping properties described above are obtained in the measurements of the tubular samples. The pumping properties of the columnar $\mathrm{Zr}$ tube were repeated on five different samples in total with pumping properties similar to those reported in this paper and earlier publications $[14,15]$. Although the $R$ criterion has not indicated pure $\mathrm{Zr}$ as a good candidate, the pumping properties measurements demonstrate that it is. This can be explained by two main points: the conditions of the surface inside the NEG coated tube with a large aspect ratio is different to the ones on planar samples inside an Auger/XPS chamber and the criteria might not be correct for comparing different NEG coating compositions. Since the results of direct pumping properties measurements are repeatable and reliable, they should be used a primary criteria for the vacuum film performance rather than Auger/XPS characterisation.

\subsection{ESD results}

ESD yields as a function of the amount of desorbed gas, shown in Fig. 10, allow one to obtain another parameter that is important when designing a vacuum system, enabling specification of the pumping parameters of the lump pumps used between vacuum chambers in accelerator vacuum system.

Table 3 summarises a comparison of the amount of desorbed gas for dense and columnar films activated to different temperatures corresponding to the electron dose of $2.7 \times 10^{24} \mathrm{e}^{-/} / \mathrm{m}^{2}$. One can see that for non-activated NEG, the columnar film desorbs much greater amount of $\mathrm{H}_{2}, \mathrm{CH}_{4}$ and $\mathrm{CO}$ than the dense film. That means with the same mechanical design, the dense film would require fewer pumps with lower pumping speed and sorption capacity. Similarly, there is also a clear benefit of using the dense NEG activated to $150{ }^{\circ} \mathrm{C}$ in comparison to the columnar film. However, after activation to $180{ }^{\circ} \mathrm{C}$, these values of the amount of desorbed gas become comparable for both films. For higher activation temperatures, the results are the opposite - the total amount of desorbed gas from the dense film is higher than from the columnar film. This could be explained by defining the sources of gas and molecular beam dynamics inside the substrate, inside the NEG coated film and on the surface of the NEG film.

Owing to the larger physical surface are of the columnar NEG, the amount of gas contained near the surface is larger; therefore, it can be more easily released from the columnar structure after baking to $80{ }^{\circ} \mathrm{C}$. Diffusion of the gas from the bulk of the substrate and the NEG film is negligible.

Activation to $150{ }^{\circ} \mathrm{C}$ is very likely affecting the gas near the surface; this reduces ESD and the amount of gas desorbed from both dense and columnar coatings, but ESD from the columnar coating is still larger due to a larger surface area - the effect of volume of both NEG film and the substrate is still negligible.

Activation to $180{ }^{\circ} \mathrm{C}$ is likely to involve the diffusion of $\mathrm{H}, \mathrm{C}$ and $\mathrm{O}$ from the bulk of the NEG films. However, it is different for columnar and dense films. The $\mathrm{H}_{2}$ yield in Fig. 10(b) remains almost the same for the doses between $7 \times 10^{23} \mathrm{e}^{\mathrm{e} / \mathrm{m}^{2}}$ until the end of experiment with $\mathrm{D}=7 \times 10^{24} \mathrm{e}^{\mathrm{e} / \mathrm{m}^{2}}$. This happens due to $\mathrm{H}$ diffusion from the substrate through the NEG film. However, the dense film is still acting as a good $\mathrm{H}$ barrier at this temperature.

For the higher activation temperatures, the efficiency of depleting the substrate and the NEG film of hydrogen is more efficient for the columnar NEG due to its transparency, while the dense NEG barrier properties also reduces the depletion process.

Figures 11 and 12 show how sticking probability changes before and after the ESD experiments (as described in section 3.2) and give a comparison to the initial results obtained during injection experiments (described in section 3.1). For non-activated NEG coating, the initial sticking probability is equal to zero, while at the end of electron 
bombardment NEG coating is partially activated, demonstrating $\alpha_{0}\left(\mathrm{H}_{2}\right)=5 \times 10^{-4}$ and $\alpha_{0}(\mathrm{CO})=1.1 \times 10^{-3}$ for dense and $\alpha_{0}\left(\mathrm{H}_{2}\right)=1 \times 10^{-2}$ and $\alpha_{0}(\mathrm{CO})=4.3 \times 10^{-2}$ for columnar films. These results are known as photon or electron bombardment induced NEG coating activation, demonstrated by the authors in previous publications [10,20]. For the activated NEG coating, one can note that for both types of coating, the sticking probabilities determined before ESD measurements are lower than the sticking probabilities obtained originally. This could be explained by considering the lifetime of the coating and the number of activations that it had endured by that point. By the time ESD measurements started, both samples were activated to various temperatures around ten times, and it has affected the quality of the $\mathrm{Zr}$ coating on the substrate.

The effectiveness of activation by the electron bombardment can be evaluated by comparing sticking probabilities before and after ESD experiments. The sticking probability of the dense coating does not change significantly, except for $\mathrm{CO}$ after activation to $180{ }^{\circ} \mathrm{C}$, when $\alpha_{0}(\mathrm{CO})$ increased by a factor 1.7 . For the columnar coating, the sticking probabilities increased by a factor less than 2 for $\mathrm{H}_{2}$ activated to 180 and $200{ }^{\circ} \mathrm{C}$, and by a factor of 6.5 for $\mathrm{CO}$ after activation to $150{ }^{\circ} \mathrm{C}$, but no significant changes in other runs were observed. This proves that the NEG coating can be further activated to a higher degree by using electron bombardment. However, the electron induced NEG activation only takes place when the NEG coating is either not activated or not fully activated: no increase in sticking probability after electron bombardment has been observed for the NEG coating activated to $200{ }^{\circ} \mathrm{C}$ (high degree of activation).

This effect of bombardment induced NEG coating activation is extremely important for particle accelerators, where fitting heating equipment would be impossible and where electron and photon stimulated desorption is a naturally occurring phenomena. These experimental results also demonstrate that the columnar $\mathrm{Zr}$ coating can be activated and fully saturated multiple times while maintaining most of its pumping capacity.

To explore further the aging effect of the coating after exposing the sample to air for one year, the $\mathrm{H}_{2}$ and $\mathrm{CO}$ sticking probabilities for the columnar sample were measured and compared before and after the exposure. Figure 13 demonstrates that after one year exposure to air, the $\mathrm{H}_{2}$ and $\mathrm{CO}$ sticking probabilities for $140 \leq T_{s} \leq 300{ }^{\circ} \mathrm{C}$ are lower than the ones before exposure. However, the difference between the two reduces with temperature from about an order of magnitude for $T_{s} \leq 140^{\circ} \mathrm{C}$ to a factor of $\sim 1.5$ for $T_{s} \leq 300{ }^{\circ} \mathrm{C}$. This demonstrates that to preserve pumping properties, a $\mathrm{Zr}$-coated tube should be stored preferably in vacuum or in a neutral gas (noble gases or $\mathrm{N}_{2}$ ) atmosphere.

\section{CONCLUSIONS}

Pumping properties and ESD yields of dense and columnar single metal $\mathrm{Zr}$ coatings have been measured.

The columnar Zr NEG coating has demonstrated good pumping properties with an activation temperature as low as $160{ }^{\circ} \mathrm{C}$ and $\mathrm{CO}$ capacity of a few monolayers. ESD yields after activation to $150{ }^{\circ} \mathrm{C}$ are reduced significantly in comparison to non-activated NEG. After activation to $180{ }^{\circ} \mathrm{C}$, the ESD yields are reduced further down; activations to higher temperatures reduced yields insignificantly.

For the dense film, the $\mathrm{H}_{2}$ pumping properties are reaching maximum for $T_{s} \geq 180{ }^{\circ} \mathrm{C}$ and the $\mathrm{CO}$ pumping properties improve in the whole range of temperature. In general, the $\mathrm{H}_{2}$ and $\mathrm{CO}$ sticking probabilities and CO sorption capacity of the dense film are lower than the columnar ones. The lowest ESD yields are achieved after activation to $150-180{ }^{\circ} \mathrm{C}$, these values are approximately an order of magnitude lower than for the columnar one. Higher activation temperatures result in increased ESD yields.

Therefore, $T_{s}=180^{\circ} \mathrm{C}$ looks optimal for both films. 
These results are comparable to the results achieved with quaternary Ti-Zr-Hf-V coating and better than the properties of the ternary Ti-Zr-V film. While the sticking probability and CO pumping capacity of the dense film are considerably lower than that of the columnar film, the dense coating acts as a better barrier between chamber walls and inner vacuum. One can conclude that single metal columnar $\mathrm{Zr}$ coating is a good candidate for the coating of accelerator vacuum chambers due to the wider availability of a single metal target and a lower cost of $\mathrm{Zr}$, compared to $\mathrm{Hf}$ and $\mathrm{V}$ or alloys. Furthermore, the deposition process is simplified when single a metal is used.

\section{ACKNOWLEDGMENTS}

This work was conducted under the aegis of the Science and Technology Facilities Council. The authors would also like to acknowledge the support provided by European Union's H2020 Framework Programmes awarded to the Science and Technology Facilities Council: EuroCirCol collaboration under grant agreement no. 654305.

\section{REFERENCES}

[1] C. Benvenuti, "Non-evaporable getters: from pumping strips to thin film coatings", in Proc. EPAC-1998, Stockholm, Sweden, June 1998, pp. 200-204.

[2] C. Benvenuti, P Chiggiato, F. Cicoira and V. Ruzinov, "Decreasing surface outgassing by thin film getter coatings", Vacuum 50, p. 57 (1998).

[3] C. Benvenuti et al., "Vacuum properties of TiZrV non-evaporable getter films", Vacuum 60, p. 57 (2001).

[4] C. Benvenuti, P. Chiggiato, A. Mongelluzzo, A. Prodromides, V. Ruzinov, C. Scheuerlein, M. Taborelli, "Influence of the elemental composition and crystal structure on the vacuum properties of Ti-Zr-V nonevaporable getter films", J. Vac. Sci. Technol. A 19, p. 2925 (2001).

[5] A. Prodromides, C. Scheuerlein, M. Taborelli, "Lowering the activation temperature of TiZrV non-evaporable getter films", Vacuum 60, p. 35 (2001).

[6] C. Benvenuti, A. Escudeiro Santana, V. Ruzinov, "Ultimate pressures achieved in TiZrV sputter-coated vacuum chambers", Vacuum 60, p. 279 (2001).

[7] R. Valizadeh, O. B. Malyshev, J. S. Colligon, A. Hannah, V. M. Vishnyakov, "Comparison of Ti-Zr-V nonevaporable getter films deposited using alloy or twisted wire sputter-targets”, J. Vac. Sci. Technol. A 28, p. 1404 (2010).

[8] O. B. Malyshev, R. Valizadeh, A. N. Hannah, "Pumping properties of Ti-Zr-Hf-V coating”, Vacuum 100, p. 26 (2014).

[9] O. B. Malyshev, R. Valizadeh, "Further optimisation of NEG coatings for accelerator beam chamber", in Proc. IPAC-2014, Dresden, Germany, 2014, pp. 2399-2402.

[10] O. B. Malyshev, A. Smith, R. Valizadeh, A. N. Hannah, "Electron stimulated desorption from bare and nonevaporable getter coated stainless steels", J. Vac. Sci. Technol. A 28, pp. 1215-1225 (2010).

[11] O. B. Malyshev, R. Valizadeh, R. M. A. Jones, A. N. Hannah, "Effect of coating morphology on the electron stimulated desorption from Ti-Zr-Hf-V nonevaporable-getter-coated stainless steel”, Vacuum 86, pp. 2035-2039 (2012).

[12] O. B. Malyshev, R. Valizadeh, B. T. Hogan, A. N. Hannah, "Electron-stimulated desorption from polished and vacuum fired 316LN stainless steel coated with Ti-Zr-Hf-V”, J. Vac. Sci. Technol. A 32, p. 61601 (2014).

[13] O. B. Malyshev, R. Valizadeh, A. N. Hannah, "Pumping and electron-stimulated desorption properties of a dual-layer nonevaporable getter", J. Vac. Sci. Technol. A 34, p. 61602 (2016).

[14] O. B. Malyshev, R. Valizadeh, presented at the $12^{\text {th }}$ European vacuum Conference, Dubrovnik, Croatia, 4-8 June 2012. 
[15] O. B. Malyshev, "Vacuum in particle accelerators: modelling, design and operation of beam vacuum systems", Wiley, pp. 190193 (2019).

[16] O. B. Malyshev, K. L. Middleman, J. S. Colligon, R. Valizadeh, “Activation and measurement of nonevaporable getter films”, $J$. Vac. Sci. Technol. A 27, p. 321 (2009).

[17] O. B. Malyshev, K. L. Middleman, “Test Particle Monte-Carlo modelling of installations of NEG film pumping properties evaluation”, Vacuum 83, p. 976 (2009).

[18] R. Kersevan, M. Ady, MolFlow+ user guide, CERN, 2014.

[19] O. Seify, O. B. Malyshev, R.Sirvinskaite, R. Valizadeh, A. N. Hannah, "Optimisation of the RGA location in the evaluation of NEG coating pumping properties", Vacuum 165, pp. 207-214 (2019).

[20] V. V. Anashin, I. R. Collins, R. V. Dostovalov, N. V. Fedorov, A. A. Krasnov, O. B. Malyshev, V. L. Ruzinov, , “Comparative study of photodesorption from TiZrV coated and uncoated stainless steel vacuum chambers”, Vacuum 75, p. 155-159 (2004). 